\title{
Modulation of Semaphorin3A Activity by p75 Neurotrophin Receptor Influences Peripheral Axon Patterning
}

\author{
Ayal Ben-Zvi, Liat Ben-Gigi, Hagit Klein, and Oded Behar \\ The Hubert H. Humphrey Center for Experimental Medicine and Cancer Research, The Hebrew University Faculty of Medicine, Jerusalem 91120, Israel
}

\begin{abstract}
The p75 neurotrophin receptor $\left(\mathrm{p} 75^{\mathrm{NTR}}\right)$ interacts with multiple ligands and coreceptors. It is thought to mediate myelin growth inhibition as part of the Nogo receptor complex, in addition to its other roles. Paradoxically, however, peripheral axons of p $75^{\text {ExonIII- }-1-}$ mutant embryos are severely stunted. This inhibition of axon growth may be a result of neurite elongation defects in p $75^{\text {NTR }}$ mutant neurons. Here, we show that $75^{\text {ExonIII-I- }}$ DRG neurons are hypersensitive to the repellent molecule Semaphorin3A (Sema3A). NGF modulates Sema3A activity equally well in both the $\mathrm{p} 75^{\mathrm{NTR}}$ mutant and wild-type neurons, indicating that the hypersensitivity of p $75^{\mathrm{NTR}}$ mutant neurons is probably not related to their NGF receptor activity. Neuropilin1 and p $75^{\text {NTR }}$ partially colocalize in DRG growth cones. After Sema3A stimulation, the degree of colocalization is dramatically increased, particularly in clusters associated with Sema3A receptor complex activation. Coimmunoprecipitation studies show that $\mathrm{p} 75^{\mathrm{NTR}}$ interacts directly with the Sema3A receptors Neuropilin1 and PlexinA4. When coexpressed with both Neuropilin1 and PlexinA4, $\mathrm{p} 75^{\mathrm{NTR}}$ reduces the interaction between these two receptor components. Finally, $\mathrm{p} 75^{\mathrm{NTR}} / \mathrm{Sema} 3 \mathrm{~A}$ double-mutant embryos show growth similar to that observed in Sema3A-null mice. These data indicate that $\mathrm{p} 75^{\mathrm{NTR}}$ is an important functional modulator of Sema3A activity and that, in the absence of $\mathrm{p} 75^{\mathrm{NTR}}$, oversensitivity to Sema3A leads to severe reduction in sensory innervation. Our results also suggest that while inhibition of p $75^{\text {NTR }}$ in CNS injury may enhance nerve regeneration resulting from the inhibition of myelin-associated protein, it may also inhibit nerve regeneration through its modulation of Sema3A.
\end{abstract}

Key words: axon guidance; development; dorsal root ganglion; DRG; knock-out mice; nerve growth factor; NGF; regeneration

\section{Introduction}

p $75^{\mathrm{NTR}}$ interacts with multiple coreceptors and ligands (Bandtlow and Dechant, 2004). Examples include the $\mathrm{p} 75^{\mathrm{NTR}} /$ sortilin complex, which mediates cell death by proneurotrophins, the Trk receptor/p $75^{\mathrm{NTR}}$ complex, which mediates neuronal survival by neurotrophins and the Nogo-R/lingo/p $75^{\mathrm{NTR}}$ complex, which mediates inhibition of regeneration by Nogo, myelin-associated glycoprotein (MAG), and oligodendrocyte myelin glycoprotein (OMgP) (Nykjaer et al., 2005). Additional independent effects of p $75^{\mathrm{NTR}}$ have also been reported (Nykjaer et al., 2005). The results of targeted mutation of the $\mathrm{p} 75^{\mathrm{NTR}}$ show that $\mathrm{p} 75^{\mathrm{NTR}}$ is involved in several aspects of central and peripheral innervation (Lee et al., 1992; McQuillen et al., 2002). One of the most striking characteristics of $\mathrm{p} 75^{\mathrm{NTR}}$ mutants is a dramatic reduction in sensory and sympathetic innervation (Lee et al., 1994; Bergmann et al., 1997; Yamashita et al., 1999). The sensory innervation defect is likely to be a developmental defect, because peripheral axons

Received Nov. 1, 2006; revised Sept. 11, 2007; accepted 0ct. 11, 2007.

This work was supported by Israel Science Foundation Grant 573/04. We thank Drs. Yves-Alain Barde, Moses Chao, Stephen Strittmatter, Marc Tessier-Lavigne, Elior Peles, and Zhigang He for the gifts of DNA constructs. We are grateful to Dr. Norman Grover (Department of Experimental Medicine, Hebrew University, Jerusalem, Israel) for his helpful advice regarding the statistical analyses, and Dr. Ilan Hammel (Department of Pathology, Tel Aviv University, Tel Aviv, Israel) for helpful advice on the use of stereological principles to estimate total axon length.

Correspondence should be addressed to Oded Behar, The Hubert H. Humphrey Center for Experimental Medicine and Cancer Research, The Hebrew University Faculty of Medicine, P.0. Box 12272, Jerusalem 91120, Israel. E-mail: odedb@md.huji.ac.il.

D0I:10.1523/JNEUROSCI.3373-07.2007

Copyright $\odot 2007$ Society for Neuroscience $\quad 0270-6474 / 07 / 2713000-12 \$ 15.00 / 0$ from embryonic day 11.5 (E11.5)-E14.5 p75 ${ }^{\mathrm{NTR}}$ mutant embryos are severely stunted and poorly arborized (Yamashita et al., 1999; Bentley and Lee, 2000). In adult p $75^{\mathrm{NTR}}$ mutants, this reduction in innervation correlates with a loss of heat sensitivity and is associated with the development of ulcers in the distal extremities (Lee et al., 1992). The formation of functional sensory networks is critically dependent on the ability of neurons to extend axons to remote targets in an accurate and timely manner. Signaling molecules tightly regulate all parameters of axon trajectories to ensure the proper formation of the peripheral nervous system (Wen and Zheng, 2006). The cause of the dramatic reduction in sensory innervation in $\mathrm{p} 75^{\mathrm{NTR}}$ mutants is not entirely clear. In growth assays, axons of p $75^{\text {NTR }}$ mutant neurons have been shown to grow slightly more slowly than those of wild-type neurons (Bentley and Lee, 2000). This effect, however, is quite small and it is difficult to understand how it could result in such a pronounced defect in vivo. An alternative explanation for the reduction in sensory axon growth in $\mathrm{p} 75^{\mathrm{NTR}}$ mutant mice may be based on the enhancement of an axon growth inhibition signal. How does $\mathrm{p} 75^{\mathrm{NTR}}$ affect axon growth inhibition? It is possible that there could be a reduction in tropomyosin-related kinase A (TrkA) signaling resulting from the reduced affinity of NGF in the absence of $\mathrm{p} 75^{\mathrm{NTR}}$.

Sema3A's activity as a powerful negative regulator of axon growth (Togashi et al., 2006) and guidance has been well documented (Taniguchi et al., 1997; Ulupinar et al., 1999; Nakamura et al., 2000; White and Behar, 2000). In Sema3A-null mice, sen- 
sory axons have been shown to penetrate inappropriate fields and overshoot the front observed in wild-type embryos, resulting in increased growth (Taniguchi et al., 1997). A number of studies have documented the role of NGF as a negative regulator of Sema3A activity (Tuttle and O'Leary, 1998; Dontchev and Letourneau, 2002; Tang et al., 2004). It is possible that, in the absence of $\mathrm{p} 75^{\mathrm{NTR}}$, sensory axon growth is inhibited because of the reduced ability of NGF to regulate Sema3A repulsion activity. In this study, we tested the hypothesis that the $\mathrm{p} 75^{\mathrm{NTR}}$ sensory axon growth defect is a result of this mutation's effect on Sema3A activity.

\section{Materials and Methods}

\section{Antibodies, growth factors, and materials}

NGF was obtained from Sigma (St. Louis, MO). The anti-HA, anti-myc, and anti-FLAG antibodies were purchased from Cell Signaling Technologies (Danvers, MA). Anti-FLAG was purchased from Sigma. Antineurofilament $2 \mathrm{H} 3$ (developed by Thomas M. Jesell and Jane Dodd, Columbia University, New York, NY) was obtained from the Developmental Studies Hybridoma Bank developed under the auspices of the National Institute of Child Health and Human Development and maintained by the University of Iowa, Department of Biological Sciences. Anti-p $75^{\text {NTR }}$ for the immunofluorescence studies was purchased from Millipore (Temecula, CA). The anti-p $75^{\mathrm{NTR}}$ (directed to the extracellular domain) used in Western blot analyses was purchased from Alamone Labs (Jerusalem, Israel). Anti-Neuropilin1 was purchased from Neuromics (Edina, MN). Secondary antibodies were obtained from Jackson Immunoresearch Laboratories (Jackson, PA).

Protease inhibitor mixture was obtained from Roche Diagnostics (Mannheim, Germany), Matrigel from BD Biosciences (Franklin Lakes, $\mathrm{NJ}$ ) and rhodamine phalloidin and Opti-MEM from Invitrogen (Carlsbad, CA). Tissue culture reagents were purchased from Biological Industries (Kibbutz Beit Haemek, Israel). All other reagents were purchased from Sigma.

\section{Expression plasmids}

The following plasmids were generous gifts from other researchers: pFlag-CMV-NP1, pCMV-myc-PlexinA4, and p-CMV-Flag-PlexinA4 from Dr. Marc Tessier-Lavigne (Genentech, San Francisco, CA); mycNP1 from Dr. Stephen Strittmatter; pCDNA-HA-p $75^{\text {NTR }}$ and pFLAGCMV2- $\gamma \mathrm{ICD}$ from Dr. Moses Chao; pCDNA3-p75 ${ }^{\mathrm{ICD}}$ (intracellular domain of $p 75^{\mathrm{NTR}}$ ) and pCDNA3-p75 ${ }^{\mathrm{ECD}}$ (extracellular domain of p $75^{\text {NTR }}$ ) from Dr. Yves-Alain Barde (University of Basel, Switzerland) and pCDNA3-myc-Necl5 from Dr. Elior Peles (Weizmann Institute of Science, Rehovot, Israel). pcDNA3 was obtained from Invitrogen and pEGFP-N1 was obtained from Clontech (Mountain View, CA).

\section{Animals}

Pregnant mice were obtained after overnight mating (day of vaginal plug is defined as embryonic day 0.5). For the $\mathrm{p} 75^{\mathrm{NTR}}$ experiments, we used the p75 NTRExonIII-null mutant (Lee et al., 1992) obtained from The Jackson Laboratory (Bar Harbor, ME). p75 ${ }^{\text {NTR }}$ embryos were genotyped using the following primers: 5' AGTATGTCCGCTCCCTGTGT, 5' CCCTTCCTCACGAATCTAGC and $5^{\prime}$ ACCAAATTAAGGGCCAGCTC. Sema3A-null mice have been described previously (Behar et al., 1996). Sema3A embryos were genotyped using the following PCR primers: 5' TGATGGCGAAAAGACTGTGT, 5' CACACGCACAGAGGAATC and 5' ACCAAATTAAGGGCCAGCTC.

Animal handling adhered strictly to national and institutional guidelines for animal research and was approved by the ethics committee of our institution.

\section{Growth cone collapse}

DRG explants were tested for growth cone collapse, as described previously (Behar et al., 1999; Ben-Zvi et al., 2006). Each experiment included three to four wells (each set of wells represented explants from a single embryo; 100-200 growth cones per well) and was repeated using five to seven embryos for each genotype. The growth cones were counted by an observer who was blind to the identities of the treatments.

\section{Neurite outgrowth assay}

DRG explants were grown for $20 \mathrm{~h}$. At this time $(t=0)$, medium was changed and the explants were grown for an additional $6 \mathrm{~h}$ with or without Sema3A. Explants were photographed at $t=0$ and after $6 \mathrm{~h}$. To monitor a large number of neurites, we divided each explant into four quarters (see Fig. $1 B$, diagram) and photographed these same quarters at $t=0$ and $t=6 \mathrm{~h}$. The lengths of the explants' neurites were measured using Image-Pro software and the differences between the lengths at $t=$ 0 and $t=6$ were calculated (growth rate was calculated by dividing the change in length by the duration of the experiment).

\section{COS-7 contraction assay}

A COS cell contraction assay was performed essentially as described by Turner and Hall (2006), with minor modifications. COS-7 cells were maintained in DMEM supplemented with $10 \%$ fetal bovine serum. Cells were transfected with $1000 \mathrm{ng}$ cDNA. In all experiments, cells were transfected with expression vectors for enhanced green fluorescent protein (pEGFP) (100 ng) and Neuropilin1 (256 ng). The other expression vectors were used as follows. PlexinA4 (385 ng), p7 ${ }^{\text {NTR }}$ (100 or $260 \mathrm{ng}$ ), nectin-like 5 (Necl5; $260 \mathrm{ng}$ ), and pcDNA3 were used to bring the total concentration to $1000 \mathrm{ng}$. Fugene6 (Roche Diagnostics) was used as a transfection reagent in all experiments. The cells were replated on glass coverslips after $12 \mathrm{~h}$. After $24 \mathrm{~h}$ of growth, Sema3A ( $1 \mathrm{nM}$ ) was added to each well and the cells were incubated for $40 \mathrm{~min}$. Cells were then fixed in $4 \%$ paraformaldehyde, washed once in PBS and visualized for GFP. Cell images were captured using a fluorescence microscope (Olympus, Hamburg, Germany) equipped with a cooled CCD camera (Roper Scientific, Duluth, GA) and a $20 \times$ objective. The cells were counted and classified according to their morphology by an observer who was blind to the identities of the treatments.

\section{Cell lysis, immunoprecipitations, and Western blots}

Cultures were lysed in a buffer containing $20 \mathrm{~mm}$ Tris, $150 \mathrm{~mm} \mathrm{NaCl}, 2$ mM EDTA, $1 \%$ NP-40 and protease inhibitors. Antibodies were added to $700 \mu \mathrm{l}$ of lysate containing $1 \mathrm{mg}$ of protein. Immunocomplexes were precipitated with $150 \mu \mathrm{l}$ of protein A Sepharose beads (Amersham Biosciences, Piscataway, NJ), washed and resuspended in SDS-PAGE loading buffer containing $\beta$-mercaptoethanol. Each immunoprecipitate was loaded in one lane of a 10 -lane, $6 \%$ polyacrylamide mini-gel. Western blot analysis was performed as previously described (Ben-Zvi et al., 2006).

\section{Sema3A}

Partially purified Sema3A was prepared as described previously (Ben-Zvi et al., 2006).

\section{Whole-mount neurofilament staining}

Whole-mount immunostaining with $2 \mathrm{H} 3$ was performed essentially as described by Kitsukawa et al. (1997). In brief, embryos were fixed for $2 \mathrm{~h}$ in $4 \%$ paraformaldehyde and $10 \mathrm{~mm}$ PBS, $\mathrm{pH} 7.0$,, washed three times in PBS plus $0.2 \%$ Triton $\mathrm{X}-100$ and dehydrated through a methanol series. Endogenous peroxidase activity was quenched overnight at $4^{\circ} \mathrm{C}$ with $80 \% \mathrm{MeOH}$ and $3 \% \mathrm{H}_{2} \mathrm{O}_{2}$, followed by rehydration through a methanol series. After a $3 \mathrm{~h}$ washing with a Tris-buffered saline solution containing $0.2 \%$ Triton X-100 (PBST), the embryos were incubated with the antibody $2 \mathrm{H} 3$ (1:100 dilution of $2 \mathrm{H} 3$ hybridoma culture supernatant with PBST-containing $2 \%$ skim milk) for $3-4 \mathrm{~d}$ at $4^{\circ} \mathrm{C}$. The embryos were then incubated for $1 \mathrm{~d}$ with HRP-coupled anti-mouse Ig antibody (The Jackson Laboratory; 1:200 dilution in PBST containing 2\% skim milk, $2 \%$ goat serum). HRP activity was detected with diaminobenzidine.

\section{Confocal microscopy and quantitative colocalization}

DRG neurons were fixed in 4\% paraformaldehyde and 10\% sucrose. Cells were incubated overnight at $4^{\circ} \mathrm{C}$ with primary antibodies diluted in PBS containing 5\% BSA, either with or without $0.1 \%$ Triton X-100. The cells were washed on the following day and then incubated with Cy3(1:100) and fluorescein-5-isothiocyanate (FITC)-conjugated (1:200) antibodies (The Jackson Laboratory). Stainings were analyzed using a laserscanning confocal microscope (Olympus IX70). Images were captured using a $100 \times$ oil objective (numerical aperture 1.4) at room temperature 
and confocal acquisition software (Fluoview; Olympus). The interval between imaged optical sections was $0.2-0.3 \mu \mathrm{m}$. Sequential scanning for Cy3 (emission, 570-640 nm) and FITC (emission, 510-530 nm) was performed.

Quantitative colocalization of Neuropilin 1 (NP1) and p75 ${ }^{\text {NTR }}$ was calculated using ImageJ software, with the colocalization threshold plug-in (written by Tony Collins, McMaster University, Hamilton, Ontario, Canada). This plug-in quantifies colocalization. We present the percentage image volume colocalized out of the total NP1 immunofluorescence signal. To calculate the degree of overlap in Sema3A-iduced NP1 clusters, we randomly chose three such clusters in 30 different images of NP1 and then tested the degree of overlap with p $75^{\mathrm{NTR}}$ in these clusters. To generate an image representing only the colocalized pixels, we used the RG2B ImageJ plug-in (written by Christopher Philip Mauer, Northwestern University, Chicago, IL).

\section{Quantification of neurofilament staining}

Images of embryos were obtained using an SZX12 stereomicroscope (Olympus, Hamburg, Germany) equipped with a C-4040 digital camera (Olympus). Two strategies, longest axon measurement and total axon length, were used to evaluate axon growth in the embryos.

Longest axon. To estimate axon growth, we measured the length of the longest axon in the ophthalmic branch of the trigeminal nerve and normalized to the eye perimeter, or measured the longest axon in the limb, from the base of the limb, and normalized to the length of the whole limb. This parameter was measured using ImageJ software.

Total axon length. To estimate the degree of growth we measured the total axon length using stereological principles, essentially as described (Ronn et al., 2000; Mandarim-de-Lacerda, 2003). In brief, the projection of the neuronal network in each limb was superimposed on a square grid (a set of parallel lines) using Adobe (San Jose, CA) Photoshop software. The total axon length was estimated using Buffon's needle problem equation: $L=(\pi d / M 2) I$, where $L$ is the axon length, $d$ the distance between the grid lines, $I$ the number of intersections between the axons and the grid lines, and $M$ the magnification.

\section{Statistical analysis}

Collapse assay. Two statistical methods were used. (1) Fisher's exact test for $2 \times 2$ tables (performed with SPSS 13.0 software, SPSS, Chicago, IL) was used to test the significance of differences in growth cone response. We used the actual number of growth cones (collapsed or noncollapsed) pooled from three to four experiments. (2) The Mann-Whitney $U$ test (performed with SPSS 13.0 software) was used to test the significance of differences in the collapse assay results of the different embryos. We used the average ratio of collapsed versus noncollapsed growth cones from each treatment (six to eight embryos per treatment).

Neurite outgrowth assay. The Mann-Whitney $U$ test with a Bonferroni correction (performed with SPSS 13.0 software) was used to test the significance of differences in the growth rate results of the embryos of the different genotypes, using the average growth rate of each embryo (three explants per embryo, three to six embryos per genotype from 3 different litters). In addition, to test the significance of the apparent trend in the growth rates of the different genotypes, we used the Jonckheere-Terpstra test (performed using StatXact; Cytel Software Corporation, Cambridge, $\mathrm{MA})$.

COS-7 contraction assay. The significance of the differences between the responses of COS-7 cells expressing NP1/PlexinA4 and those expressing NP1/PlexinA4/Necl5 to Sema3A was determined using the Fisher's exact test for $2 \times 2$ tables. We used the actual number of cells (shrunk or normal) from three individual experiments. In the case of increasing concentrations of $\mathrm{p} 75^{\mathrm{NTR}}$ expression, we used the Cochran-Armitage trend test (performed using StatXact; Cytel Software Corporation). In both cases, individual $p$ values and the overall $p$ value as determined by the $\chi^{2}$ test for combined probabilities are presented.

In vivo neurofilament staining quantification. The significance of the differences between the normalized lengths of the longest axon in various genotypes was determined using Mann-Whitney $U$ tests, with a Bonferroni correction when appropriate. Mann-Whitney $U$ tests were used because of the small sample size. In addition, we used the Jonckheere-
Terpstra test (performed using StatXact, Cytel Software Corporation) to test the significance of the apparent trend in the total axon coverage of the different genotypes. All tests used $\alpha=0.05$.

\section{Results}

\section{Increased sensitivity of P75 ${ }^{\mathrm{NTR}}-/-\mathrm{DRG}$ neurons to Sema3A-repellent activity}

In the presence of NGF, neurons from E12.5 DRG express both TrkA and $\mathrm{p} 75^{\mathrm{NTR}}$. To examine the role of $\mathrm{p} 75^{\mathrm{NTR}}$ in Sema3A repulsion activity, E12.5 DRG neurons from either from $\mathrm{p} 75^{\mathrm{NTR}}$ mutants or their wild-type littermates were explanted in the presence of $10 \mathrm{ng} / \mathrm{ml} \mathrm{NGF}$ and their sensitivities to Sema3A were compared in a growth cone collapse assay. In the presence of 15 pM Sema3A, $50 \%$ of wild-type DRG growth cones collapsed. In contrast, under the same conditions, $73 \%$ of the $\mathrm{p} 75^{\mathrm{NTR}}$ mutant DRG growth cones collapsed (Fig. 1A, supplemental Figure 1, available at www.jneurosci.org as supplemental material). The difference between wild-type and p $75^{\mathrm{NTR}}$ mutant growth cones treated with Sema3A is highly significant $\left(p=2.79 \times 10^{-52}\right.$, as determined by a Fisher's exact test for $2 \times 2$ tables with $n=7032$ ). The difference between wild-type and $\mathrm{p} 75^{\mathrm{NTR}}$ mutant embryos is also significant ( $p=0.005$, as determined by a two-tailed MannWhitney $U$ test with $n=13$ ). A similar difference in growth cone collapse was detected in the presence of 7.5 pM Sema3A (Fig. $1 \mathrm{~A}$ ) ( $40 \%$ in wild-type embryos and $57 \%$ in p $75^{\text {NTR }}$ mutant embryos). At this concentration, the difference between wild-type and $p 75^{\text {NTR }}$ mutant embryos is also significant $(p=0.014$, twotailed Mann-Whitney $U$ test with $n=24$ ). This result demonstrates that DRG neurons are significantly more sensitive to Sema3A growth cone collapse activity in the absence of $\mathrm{p} 75^{\mathrm{NTR}}$. It is worth noting that there was no difference between wild-type and $\mathrm{p} 75^{\mathrm{NTR}}$ mutant growth cone collapse in the absence of Sema3A. This indicates that the oversensitivity of $\mathrm{p} 75^{\mathrm{NTR}}$ mutant-derived neurons is not the result of any innate tendency to collapse.

NGF is known to modulate the expression levels of NP1 in DRG neurons (Dontchev and Letourneau, 2002). To test whether the absence of $\mathrm{p} 75^{\mathrm{NTR}}$ somehow modulates the levels of NP1, we examined the presence of this protein in growth cones of wildtype and $\mathrm{p} 75^{\mathrm{NTR}}$ mutant embryos. We detected no statistically significant differences in the NPI levels of wild-type and $p 75^{\text {NTR }}$ mutant embryos ( $t$ test; $p=0.415$ ) (supplemental Fig. 2, available at www.jneurosci.org as supplemental material).

\section{Increased sensitivity of P75 ${ }^{\mathrm{NTR}}-/-$ and P75 $5^{\mathrm{NTR}}+/-$ DRG neurons to Sema3A-induced neurite outgrowth inhibition} To further examine the effects of $\mathrm{p} 75^{\mathrm{NTR}}$ with regard to the sensitivity of DRG neurons to Sema3A, explants taken from $\mathrm{p} 75^{\text {NTR }}$ mutants, heterozygotes and wild-type littermates were examined in a neurite outgrowth assay. In this experiment, we measured the difference between neurite length at the time Sema3A was added (defined as $t=0$ ) and $6 \mathrm{~h}$ later (see Materials and Methods for a detailed description). In Figure $1 B$, we show an example of one segment of an explant at time 0 and $6 \mathrm{~h}$ later (To observe a large number of neurites, we monitored four quarters of each explant, as indicated in the diagram shown in Fig. $1 B$ ). Neurons from each genotype (wild-type, heterozygous or homozygous for the mutation in the $\mathrm{p} 75^{\mathrm{NTR}}$ gene) were grown for $20 \mathrm{~h}$ before the addition of different concentrations of Sema3A ( 0,15 and 30 pM Sema3A). The average axon growth rates, with or without Sema3A, for each genotype are shown in Figure $1 C$. In the absence of Sema3A, the growth rates of each of the genotypes were not significantly different ( $51 \mu \mathrm{m} / \mathrm{h}$ for the wild-type, $54 \mu \mathrm{m} / \mathrm{h}$ for heterozygotes and 

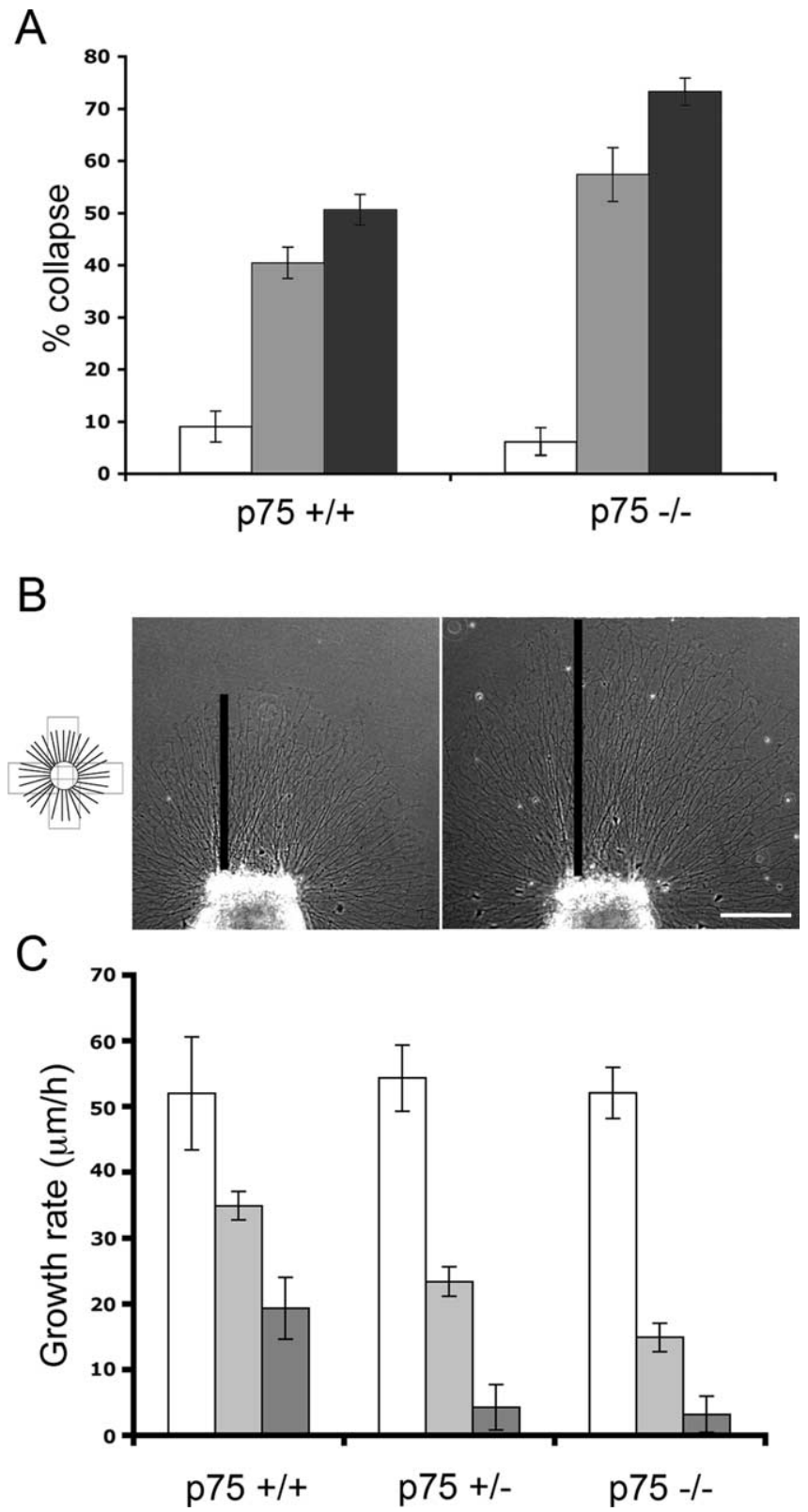

Figure 1. Increased sensitivity of $\mathrm{p} 75^{\mathrm{NTR}}-/-\mathrm{DRG}$ neurons to Sema3A repellent activity. $\boldsymbol{A}$, DRG explants from E12.5 wild-type and $\mathrm{p} 75^{\mathrm{NTR}}-1-$ mutant embryos from the same litters were grown in the presence of $10 \mathrm{ng} / \mathrm{ml} \mathrm{NGF}$ for $20 \mathrm{~h}$, at the end of which Sema3A was added. Control cultures had no Sema $3 \mathrm{~A}$ added. After an additional incubation period of $40 \mathrm{~min}$ with or without Sema3A, the explants were fixed and stained with rhodamine phalloidin. Growth cone collapse results represent the means \pm SEM of each treatment with no additional Sem $3 \mathrm{~A}$ (empty bar), 7.5 pм Sema3A (bright gray bar), or 15 pм Sema3A (dark gray bar) in four independent experiments. $B, C, D R G$ explants from E12.5 wild-type, heterozygous, and homozygous p75 ${ }^{\mathrm{NTR}}$ mutants were grown as in $A$ and treated as described in Materials and Methods. $B$, Each explant was divided into four quarters as shown in the diagram. An example of one such quarter of an explant at $t=0$ and $t=6$ is shown. Scale bar, $300 \mu \mathrm{m}$. C, Neurite outgrowth assay results represent the means \pm SEM of each treatment across three independent experiments (empty bars, no Sema3A; gray bar, 15 pм Sema3A; dark gray bar, 30 pm Sema3A).

$52 \mu \mathrm{m} / \mathrm{h}$ for homozygotes; $p=0.548$, Mann-Whitney U-Test). In contrast, there were dramatic differences in the growth rates in the presence of $15 \mathrm{pm}$ Sema3A ( $35 \mu \mathrm{m} / \mathrm{h}$ for wild-type neurons, $23 \mu \mathrm{m} / \mathrm{h}$ for heterozygotes and $15 \mu \mathrm{m} / \mathrm{h}$ for mutants). Under these conditions, heterozygous mutants exhibited an intermediate growth rate. This trend in the growth rates of the $\mathrm{p} 75^{\text {NTR }}$ genotypes was statistically significant $(p=0.01$, Jonckheere-
Terpstra test). When neurons were grown in the presence of 30 pM Sema3A, there was a similar trend in the growth rates of the different $\mathrm{p} 75^{\mathrm{NTR}}$ genotypes ( $1.9 \mu \mathrm{m} / \mathrm{h}$ for wild-type neurons, 0.4 $\mu \mathrm{m} / \mathrm{h}$ for heterozygotes, and $0.3 \mu \mathrm{m} / \mathrm{h}$ for mutant mice; $p=$ 0.049 , Jonckheere-Terpstra test). The small difference in the neurite growth of the heterozygous and homozygous mutants in the presence of $30 \mathrm{pM}$ Sema3A is probably the result of saturating concentrations of Sema3A. Based on the results of our neurite outgrowth inhibition experiment, we conclude that the growth of the $\mathrm{p} 75^{\mathrm{NTR}}$ homozygous mutant in the presence of Sema3A is much slower then that of wild-type mice, a difference that is likely to be manifested as an extensive growth redundancy in the p $75^{\text {NTR }}$ homozygous mutant at normal levels of Sema3A expression.

\section{Increased sensitivity of $\mathrm{p} 75^{\mathrm{NTR}}-/-\mathrm{DRG}$ neurons to Sema3A} is probably not mediated by NGF

NGF is a known modulator of Sema3A-induced repulsion and, at elevated concentrations, is capable of reducing Sema3A-induced growth cone collapse (Tuttle and O'Leary, 1998; Dontchev and Letourneau, 2002). Because $\mathrm{p} 75^{\mathrm{NTR}}$ is a NGF receptor, it is possible that it might mediate the NGF inhibition component and that its absence could cause an increase in neuronal sensitivity to Sema3A. To test this possibility, we examined the ability of NGF to block Sema3A-induced collapse in wild-type and mutant p $75^{\text {NTR }}$ neurons. We expected that if $\mathrm{p} 75^{\mathrm{NTR}}$ mediates the NGFdependent modulation of Sema3A, then NGF will not be able to modulate the Sema3A-induced collapse response in its absence. In this set of experiments, DRG explants from wild-type and p $75^{\text {NTR }}$ mutant embryos were grown in the presence of $2.5 \mathrm{ng} / \mathrm{ml}$ NGF for $20 \mathrm{~h}$. Thirty minutes before the addition of $15 \mathrm{pM}$ Sema3A, we added fresh medium with either $2.5 \mathrm{ng} / \mathrm{ml}$ or 40 $\mathrm{ng} / \mathrm{ml}$ NGF. Growth cone collapse was tested in both genotypes and at both concentrations of NGF. The percentage collapse at the high NGF concentration was subtracted from the percentage collapse at the low NGF concentration to calculate the growth cone collapse inhibition induced by elevated NGF concentration. The elevated concentration of NGF resulted in similar reductions in collapse rates in both wild-type $(26.58 \pm 3.41 \%$ SEM $)$ and p $75^{\text {NTR }}$ mutant neurons $(36.09 \pm 2.8 \%$ SEM). (The difference between wild-type and mutant $\mathrm{p} 75^{\mathrm{NTR}}$ is not statistically significant ( $p=0.393$ ), as determined by a two-tailed Mann-Whitney $U$ test with $n=8$ ). This experiment clearly shows that $\mathrm{p} 75^{\mathrm{NTR}}$ is not involved in the NGF-dependent modulation of Sema3A. This finding is consistent with the idea that NGF is not the reason for increased sensitivity to Sema3A in the absence of $\mathrm{p} 75^{\mathrm{NTR}}$.

\section{p75 ${ }^{\text {NTR }}$ disturbs Sema3A activity in a concentration-dependent manner}

The Sema3A receptor is a complex of PlexinA and NP1 (Nakamura et al., 2000). Previous experiments in knock-out mice suggest that PlexinA4 and, to lesser degree, PlexinA3 are important for the repulsion activity of Sema3A (Suto et al., 2005; Yaron et al., 2005). To test the ability of $\mathrm{p} 75^{\mathrm{NTR}}$ to modulate Sema3 $\mathrm{A}$ activity in a ligand-independent manner, we used the heterologous COS-7 cell contraction assay. In this assay, cDNA expression vectors for PlexinA4 and NP1 are transfected into COS-7 cells, which are challenged $48 \mathrm{~h}$ later with Sema3A. We modified the assay by adding $\mathrm{p} 75^{\mathrm{NTR}}$ or Necl5 (nectin-like-5, an unrelated neuronal receptor used as a control) expression vectors to some samples, in addition to the expression vectors for PlexinA4 and NP1. Forty-eight hours after transfection, the cells were stimulated with Sema3A (1 
A

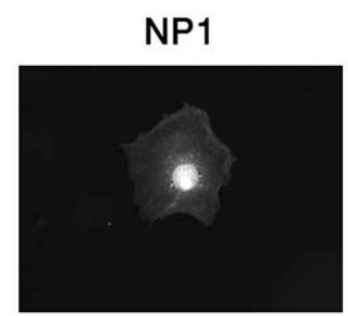

NP1/Plexin A4

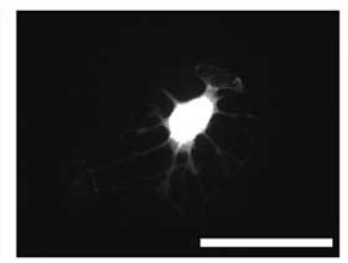

B

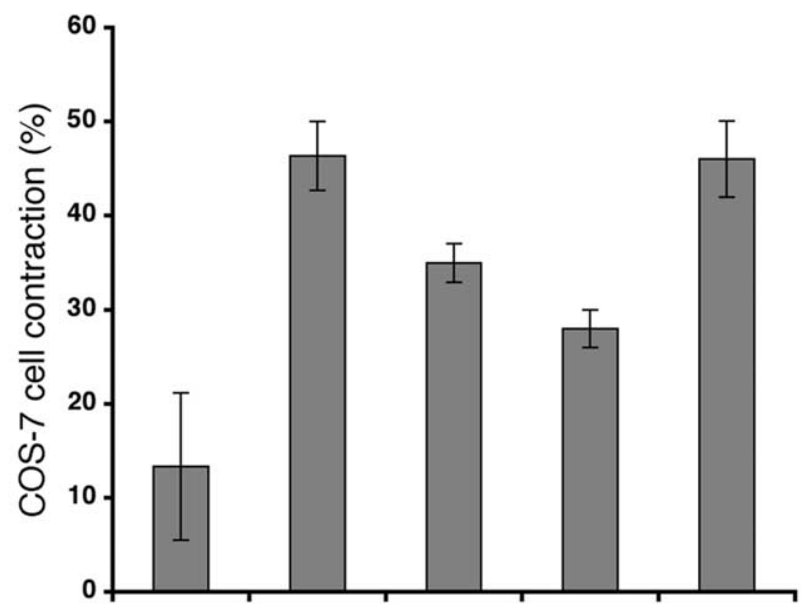

\begin{tabular}{llllll}
\hline NP1 & + & + & + & + & + \\
\hline Plexin A4 & - & + & + & + & + \\
\hline p75 & - & - & + & ++ & - \\
\hline Necl5 & - & - & - & & - \\
\hline
\end{tabular}

Figure 2. Expression of P75 ${ }^{\mathrm{NTR}}$ in $\mathrm{COS}-7$ cells reduces Sema3A activity via a PlexinA4/NP1 complex in a concentration-dependent manner. COS-7 cells were transfected with CDNA as indicated and then stimulated with Sema3A (1 nm) $48 \mathrm{~h}$ later for $40 \mathrm{~min}$. $\boldsymbol{A}, \boldsymbol{B}$, Examples of collapsed and noncollapsed transfected cells visualized using GFP expression. Scale bar, 100 $\mu \mathrm{m}$. C, The percentage of transfected cells that collapsed after Sema3A treatment was determined by fluorescence microscopy. Results represent the means \pm SEM of three independent experiments. Cells were transfected with a total of $1 \mu \mathrm{g}$ CDNA for all treatments. Ten percent of the DNA was pEGFP-N1, 38.5\% was PlexinA4, and $26.5 \%$ was NP1. p7 $5^{\mathrm{NTR}}+$ and $\mathrm{p} 75^{\mathrm{NTR}}++$ indicate that 10 and $26 \%$ of the total DNA were $775^{\text {NTR }}$, respectively. Necl5 ++ indicates that $26 \%$ of the total DNA was a Necl5 expression vector. In each transfection, the total DNA content was brought to $1 \mu \mathrm{g}$ using $\mathrm{pCDNA3}$ expression vector.

$\mathrm{nm}$ ) for $40 \mathrm{~min}$. We counted transfected cells to determine the percentage that had undergone morphological collapse (examples of collapsed and noncollapsed cells can be seen in Fig. $2 A)$. Increasing concentrations of $\mathrm{p} 75^{\mathrm{NTR}} \mathrm{cDNA}$ reduced the rate of Sem3A-induced collapse (Fig. $2 B$ ). This decrease was significant (tested in three individual experiments, $p=0.023$, $p=0.004$, and $p=0.054$, as determined by a Cochran-Armitage trend test with $n=108, n=222$ and $n=163$, respectively; overall significance is $p=0.0005$, as determined by a $\chi^{2}$ test for combined probabilities). In contrast, expression of Necl5 had no significant effect on the contraction response (tested in three individual experiments, $p=1, p=0.737$, and $p=0.697$, as determined by a Fisher's exact test for $2 \times 2$ tables with $n=$ $105, n=170$ and $n=113$, respectively; overall significance was $p=0.985$, as determined using a $\chi^{2}$ test for combined probabilities) (Fig. $2 \mathrm{~B}$ ). These experiments were done in the absence of NGF, supporting the hypothesis that inhibition of collapse by $\mathrm{p} 75^{\mathrm{NTR}}$ is ligand independent. p75 ${ }^{\mathrm{NTR}}$ and NP1 colocalize in growth cones

To begin testing whether $\mathrm{p} 75^{\mathrm{NTR}}$ can affect the Sema3A receptor complex directly, we first tested whether NP1 and p $75^{\text {NTR }}$ are colocalized in growth cones. In these experiments, primary sensory neurons and DRG explants from E13.5 embryos were cultured for $20 \mathrm{~h}$ with $10 \mathrm{ng} / \mathrm{ml} \mathrm{NGF}$. The cultures were then treated with (or without) $30 \mathrm{pm}$ Sema3A for $5 \mathrm{~min}$ and then fixed. The neurons were stained with anti-p $75^{\mathrm{NTR}}$ and anti-NP1 (Fig. 3). Anti-PlexinA4 was not tested because of its apparent unavailability. In control cultures, confocal laser microscopy revealed partial colocalization of $\mathrm{p} 75^{\mathrm{NTR}}$ and NP1 in axon shafts and growth cones (Fig. 3A). Using the ImageJ colocalization threshold plug-in software (for details, see Material and Methods), we found that the degree of colocalization in growth cones is $\sim 34 \%$ (Fig. 3C) (this result may represent a basal colocalization level of two diffusible antigens in a limited area of the growth cone). Sema3A induces rapid morphological changes that may affect the degree of colocalization nonspecifically. To circumvent this, we tested only noncollapsed growth cones. In Sema3A-treated growth cones, the degree of colocalization is $\sim 55 \%$ (Fig. $3 B, C$ ). Sema3A stimulation induces a rapid formation of membrane clusters (before growth cone collapse) that includes NP1, Plexin and the signaling molecule racl (Fournier et al., 2000). In our system, Sema3A also induces clusters of NP1. We found that the degree of $\mathrm{p} 75^{\mathrm{NTR}} / \mathrm{NP} 1$ colocalization in these clusters is higher then the overall colocalization and reaches $\sim 74 \%$. Together, the colocalization analysis indicates $\mathrm{p} 75^{\mathrm{NTR}}$ is found to a large degree in close proximity to NP1, most prominently in clusters believed to be involved in Sema3A receptor complex signaling.

\section{p75 ${ }^{\text {NTR }}$ can form a complex with the Sema3A receptor}

Because our confocal microscopy work indicated that $\mathrm{p} 75^{\mathrm{NTR}}$ and NP1 are partly colocalized in DRG axons, we tested whether p $75^{\text {NTR }}$ can also form a complex with the Sema3A receptor components. We transfected human embryonic kidney 293 (HEK293T) cells to coexpress HA-tagged p75 NTR and Flagtagged NP1 (Fig. 4A). We found that HA-p $75^{\text {NTR }}$ can be immunoprecipitated from cell extracts with immobilized anti-Flag antibody. We also observed that immunoprecipitation with antibodies to HA coimmunoprecipitated HA-p $75^{\text {NTR }}$ and FlagNP1. Total IgG failed to immunoprecipitate either HA-p $75^{\text {NTR }}$ or Flag-NP1. To further test the specificity of immunoprecipitation, we coexpressed Flag-NP1 with myc-Necl5. Myc-Necl5 and Flag-NP1 did not coimmunoprecipitate, supporting the specificity of the interaction of NP1 and p $75^{\mathrm{NTR}}$ (Fig. $4 B$ ). To test whether $\mathrm{p} 75^{\mathrm{NTR}}$ can form a complex with PlexinA4, we transfected HEK293T with HA-p75 ${ }^{\text {NTR }}$ and Flag-PlexinA4 (Fig. 4C). Anti-Flag antibody immunoprecipitated both Flag-PlexinA4 and HA-p $75^{\text {NTR }}$. Similarly, immunoprecipitation of HA-p $75^{\text {NTR }}$ resulted in immunoprecipitation of Flag-PlexinA4. Total IgG failed to immunoprecipitate either HA-p $75^{\text {NTR }}$ or Flag-PlexinA4. When we coexpressed Flag-PlexinA4 with myc-Necl5, the two proteins did not coimmunoprecipitate (data not shown).

To learn more about the interactions between NP1, PlexinA4 and $\mathrm{p} 75^{\mathrm{NTR}}$, we tested whether the intracellular $\left(\mathrm{p} 75^{\mathrm{NTR}-\mathrm{ICD}}\right)$ or extracellular ( $\mathrm{p} 75^{\mathrm{NTR}-\mathrm{ECD}}$ ) domain is important for the interactions involving PlexinA4 and NP1. As a first step, we coexpressed myc-PlexinA4 with either the Flag-p $75^{\text {NTR-ICD }}$ or the p $75^{\text {NTR- }}$ ECD (the full-length $\mathrm{p} 75^{\mathrm{NTR}}$ was used as a control in each experiment) (data not shown). As shown in Figure $4 D$, the extracellular domain of $\mathrm{p} 75^{\mathrm{NTR}}$ was sufficient for the interactions with PlexinA4. In contrast, no interaction was detected between the intracellular domain of $\mathrm{p} 75^{\mathrm{NTR}}$ and PlexinA4. To test which part 

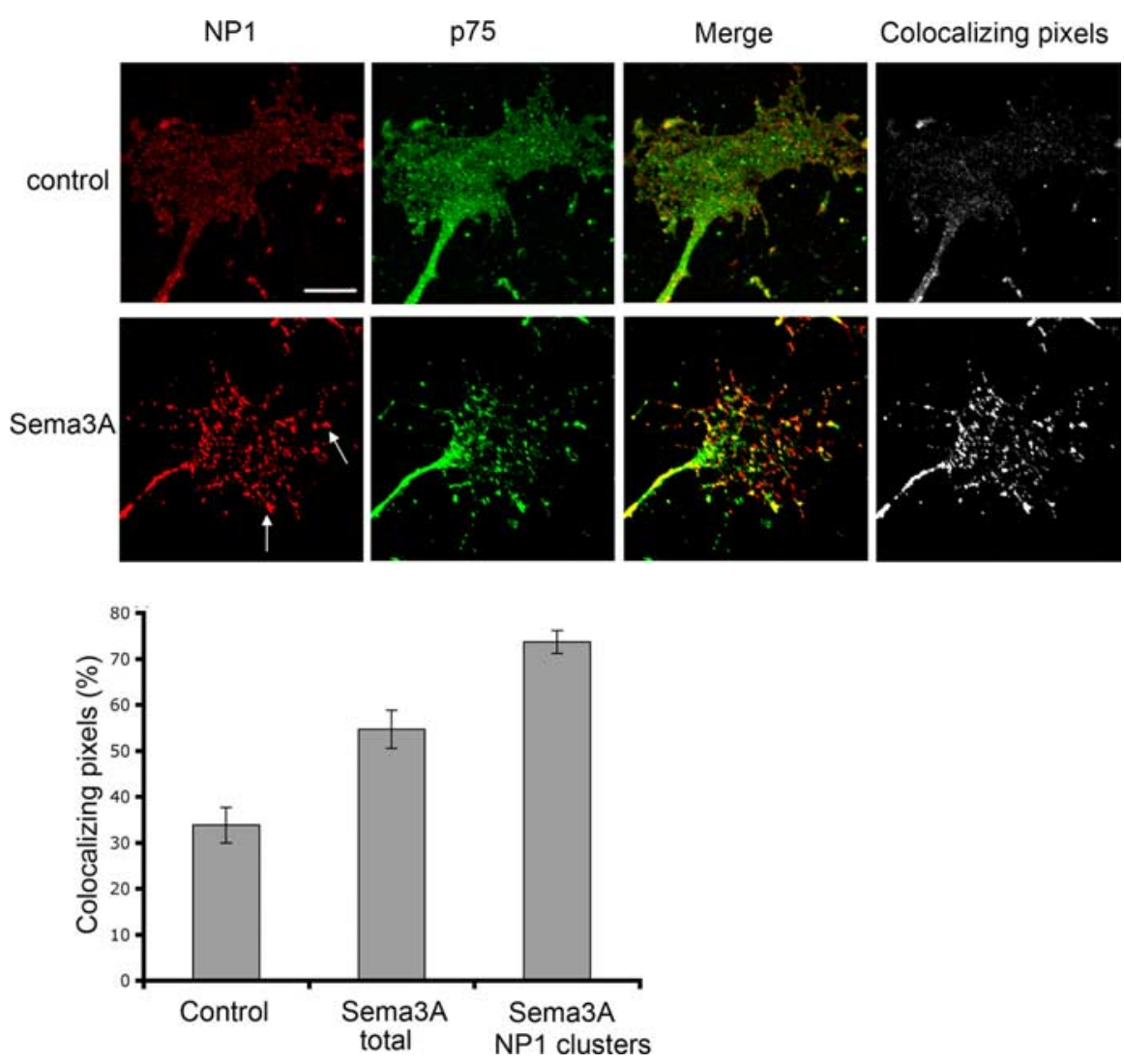

Figure 3. Colocalization of NP1 and p75 ${ }^{\text {NTR }}$ in DRG axons. Sensory axons from E13.5 were stained with anti-p75 ${ }^{\text {NTR }}$ and anti-NP1 and analyzed by confocal microscopy. Scale bar, $10 \mu \mathrm{m}$. For the control experiments, FITC-donkey anti-goat was incubated with rabbit anti-p75-labeled neurons. In addition, Cy3-donkey anti-rabbit was incubated with goat anti-NP1-labeled neurons. Acquisition parameters were defined so that background staining would show no detectable signal (data not shown). Representative optical section images of growth cones with (bottom) or without treatment (top) of 30 pm Sema3A are shown. A clear, but incomplete overlap between p75 NTR and NP1 is shown in the image of the overlap pixels (right). After Sema3A treatment, the reorganization of NP1 into clusters is visible (examples of such clusters are indicated by arrows). Quantification of the degree of overlap between NP1/p75 was measured as described in the Materials and Methods section. Each data point represents a mean \pm SEM of 30 growth cones from three independent experiments.

of p $75^{\text {NTR }}$ interacts with NP1, we coexpressed myc-NP1 with either the Flag-p $75^{\text {NTR-ICD }}$ or the $\mathrm{p} 75^{\text {NTR-ECD }}$. As shown in Figure $4 E$, the extracellular domain of $\mathrm{p} 75^{\mathrm{NTR}}$ was sufficient for the interactions with NP1. In contrast, we did not detect any interaction between NP1 and the intracellular domain of $\mathrm{p} 75^{\mathrm{NTR}}$.

To further test whether $\mathrm{p} 75^{\mathrm{NTR}}$ interacts directly with the Sema3A receptor, we tested whether the interaction between p $75^{\text {NTR }}$ and NP1 could be detected in vivo. In these experiments, we tested tissues of the DRG, spinal cord and brain. In addition, we examined DRG neuron cultures with or without Sema3A treatment. In these experiments, we immunoprecipitated p $75^{\text {NTR }}$ and tested the levels of NP1. We were unable to detect coimmunoprecipitation of NP1 in these experiments (data not shown). (We did not repeat the experiments with anti-PlexinA4 because of a lack of a suitable commercial antibody.) Our inability to detect this interaction is likely attributable to a technical difficulty. One reason for this difficulty may be the partial colocalization and the dynamic nature of the interaction between p $75^{\text {NTR }}$ and the Sema3A complex (Fig. 3). Additional interactions of $\mathrm{p} 75^{\mathrm{NTR}}$ with other molecules in these neurons (i.e., TrkA) may also interfere with stable coimmunoprecipitation. Together, it is quite possible that, in this case, coimmunoprecipitation is below the threshold level that can be detected using this technique. ments, HA-p $75^{\text {NTR }}$ immunoprecipitated with Flag-PlexinA4 when a higher concentration of the $\mathrm{p} 75^{\mathrm{NTR}}$ expression vector was used, indicating that HA-p $75^{\mathrm{NTR}}$ competes with NP1 for PlexinA4 interaction. The fact that, at the lower levels of p $75^{\text {NTR }}$ expression, only small amounts of this protein were immunoprecipitated with PlexinA4 may be explained by the formation of a $75^{\mathrm{NTR}} / \mathrm{NP} 1$ complex, which could not be detected in this experimental paradigm. These data support a model whereby $\mathrm{p} 75^{\mathrm{NTR}}$ interferes with the formation of the NP1/PlexinA4 complex. Necl5 had no effect on the ability of PlexinA4 to immunoprecipitate NP1 (data not shown), confirming the specificity of this effect of $\mathrm{p} 75^{\mathrm{NTR}}$. These results suggest that the interaction of $\mathrm{p} 75^{\mathrm{NTR}}$ with plexin or NP1 can reduce the formation of the Sema3A receptor complex, thereby reducing Sema3A activity.

\section{Growth inhibition of peripheral sensory projections in} p $75^{\text {NTR }}$ mutant embryos is alleviated in the absence of Sema3A

Using whole-mount antineurofilament immunohistochemistry, it was shown that peripheral nerves at E12.2-14.5 are severely stunted in the absence of p $75^{\text {NTR }}$ (Yamashita et al., 1999; Bentley and Lee, 2000). To test whether Sema3A contributes to this growth inhibition in $\mathrm{p} 75^{\mathrm{NTR}}$ mutant embryos, 


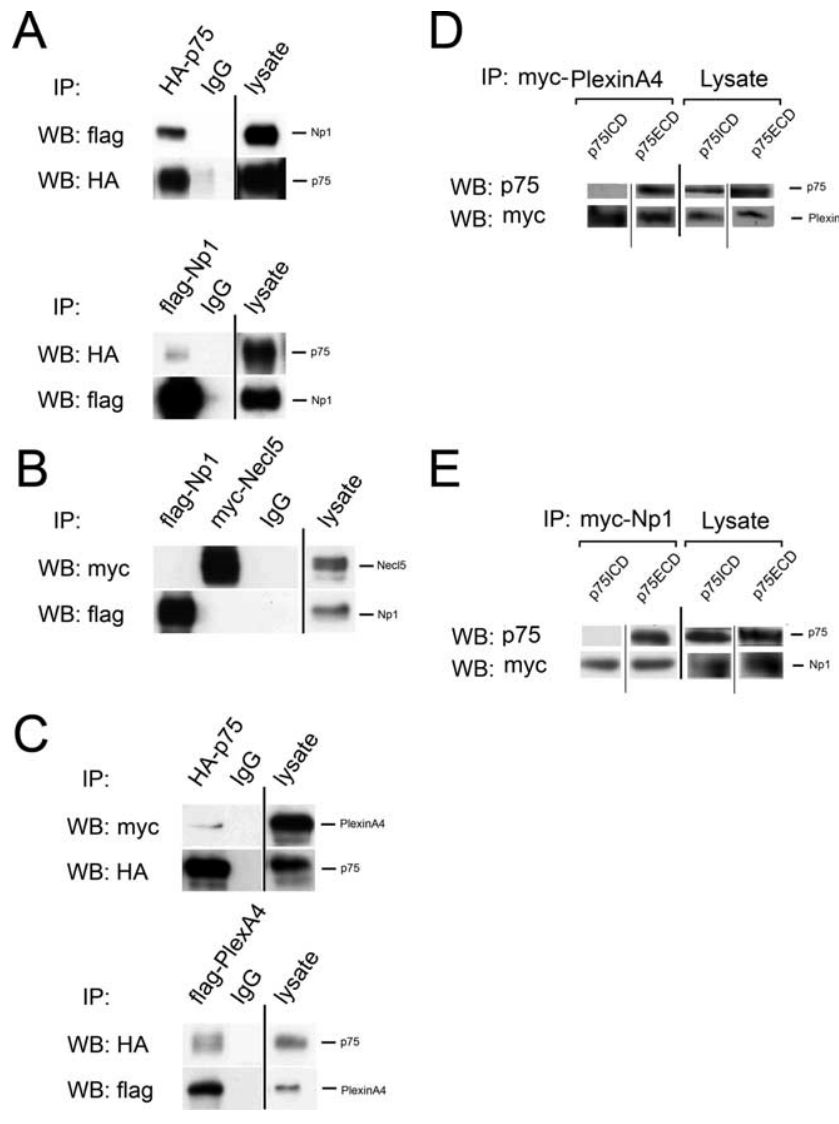

Figure 4. $\quad$ p75 $5^{\mathrm{NTR}}$ immunoprecipitates with NP1 and PlexinA4. A-E, HEK293T cells were transfected with HA-tagged p75 NTR and Flag-tagged NP1 $(\boldsymbol{A})$, myc-Necl5 (nectin-like-5) and Flag-tagged NP1 (B), HA-tagged p75 NTR and Flag-PlexinA4 or myc-PlexinA4 (C), myc-PlexinA4 and p75 ${ }^{\text {NTR-ECD }}$ (extracellular and transmembrane domains) or Flag-p $75^{\text {NTR-ICD }}$ (intracellular and transmembrane domains) (D), or myc-NP1 and p75 NTR-ECD or Flag-p75 ${ }^{\text {NTR-ICD }}(\boldsymbol{E})$. The cells were lysed $48 \mathrm{~h}$ after transfection and tested in a coimmunoprecipitation assay. The starting material (lysate) is shown at the right of each panel, the immunoprecipitation antibody is indicated above each lane, and the Western blot (WB) antibody is indicated to the left of each panel. $\boldsymbol{A}$, Cell lysates were immunoprecipitated with anti-HA-p75 (top) and blotted with antiFlag, and then with anti-HA-p $75^{\text {NTR }}$. In a separate sample, the cell lysates were immunoprecipitated with anti-Flag-NP1 and blotted with anti-HA, and then with anti-Flag (bottom). Total IgG was also used to immunoprecipitate cell lysates as a control (center lanes). $\boldsymbol{B}$, Cell lysates were immunoprecipitated with anti-Flag-NP1 or anti-myc-Necl and blotted with anti-Flag or anti-myc as indicated. C, Cell lysates were immunoprecipitated with anti-HA-p $75^{\text {NTR }}$, resulting in immunoprecipitation of myc-PlexinA4 (top). Likewise, immunoprecipitation of FlagPlexinA4 resulted in immunoprecipitation of $\mathrm{HA}-\mathrm{p} 75^{\mathrm{NTR}}$ (bottom). Total lgG failed to immunoprecipitate either $\mathrm{HA}-\mathrm{p} 75^{\mathrm{NTR}}$ or Flag-PlexinA4. D, E, Cell lysates were immunoprecipitated with anti-myc-PlexinA4 (D) or anti-myc-NP1 $(\boldsymbol{E})$ and blotted with anti-p75 extracellular domain antibody in the case of p $75^{\text {NTR-ECD }}$, or anti-Flag in the case of Flag-p $75^{\text {NTR-ICD }}$. To monitor the initial amounts of myc-Plexin A4 (D) or myc-NP1, the membranes were reblotted with anti-myc antibody.

we used double heterozygous mice $\left(\mathrm{p} 75^{\mathrm{NTR}}+/-\right.$; Sema3 A $+1-$ ) to generate wild-type, homozygous and mutant E12.5 embryos. To evaluate the effects of these different genotypes on axon growth, we focused on the limbs and the ophthalmic branch of the trigeminal ganglia of E12.5 embryos. In the limbs, we evaluated growth by measuring the longest axon normalized to the length of the measured limb. In the case of the trigeminal projections, we used the longest length criteria normalized to the eye perimeter (for details of these measurements, see Materials and Methods). As expected, peripheral nerves in hind limbs (Fig. 6A,B), forelimbs (Fig. 6C, supplemental Fig. 3, available at www.jneurosci.org as supplemental

IP: flag-PlexA4
\begin{tabular}{llllllll}
\hline & \multicolumn{3}{l}{ lysate } \\
\hline NP1 & + & + & + & + & + & + \\
\hline Plexin A4 & + & + & + & + & + & + \\
\hline p75 & - & + & ++ & - & + & ++ \\
\hline
\end{tabular}

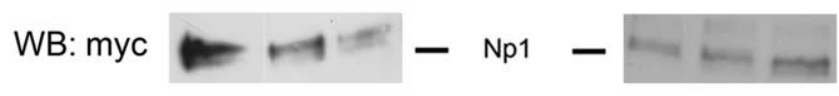

WB: flag

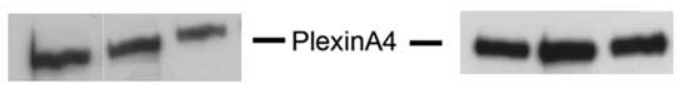

WB: HA
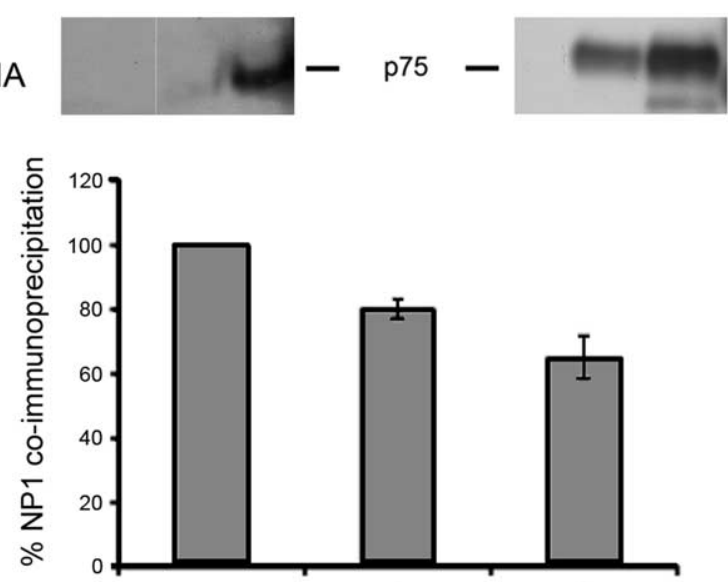

\begin{tabular}{llll}
\hline NP1 & + & + & + \\
\hline Plexin A4 & + & + & + \\
\hline p75 & - & + & + \\
\hline
\end{tabular}

Figure 5. $\mathrm{p} 75^{\mathrm{NTR}}$ neurotrophin receptor disrupts the formation of the Plexin A4/NP1 complex. Top, HEK293T cells were transfected with $4 \mu \mathrm{g}$ myc-tagged NP1 and $6 \mu \mathrm{g}$ Flag-tagged PlexinA4. In addition, the cells were transfected with increasing amounts of HA-tagged p75 NTR (+ represents $4 \mu \mathrm{g}$ of $\mathrm{p} 75^{\mathrm{NTR}} ;++$ represents $10 \mu \mathrm{g}$ ). For all transfections, total DNA was brought to $20 \mu \mathrm{g}$ using a pCDNA3 expression vector. The cells were lysed at $48 \mathrm{~h}$ after transfection and PlexinA4 was immunoprecipitated from lysates with anti-Flag antibodies. Blots were probed with anti-myc-NP1 and then reprobed, first with anti-HA-p $75^{\text {NTR }}$, and then with antiFlag-PlexinA4. Aliquots of the total cell lysates were directly probed with anti-myc-NP1, antiFlag-PlexinA4 and anti-HA-p $75^{\text {NTR }}$ as a control. (This figure was prepared by combining two parts of the same membrane to exclude a nonrelevant lane). Bottom, Quantification of NP1 coimmunoprecipitated by PlexinA4. We normalized the levels of NP1 and PlexinA4 to their expression levels in the lysate. We then divided the normalized values of NP1 by the normalized values of PlexinA4. The result of this calculation in the absence of $p 75$ was defined as $100 \%$ coimmunoprecipitation. Results represent the means \pm SEM of five independent experiments.

material), and trigeminal ganglia (Fig. 6D, supplemental Fig. 4 , available at www.jneurosci.org as supplemental material) of p $75^{\text {NTR }}$ mutant mice are all severely stunted compared with those of the control wild-type littermates $\left[p=1.25 \times 10^{-4}\right.$ (hind limb), $p=8.1 \times 10^{-5}$ (forelimbs), and $p=0.008$ (trigeminal ganglion), as determined by a one-tailed MannWhitney $U$ test with seven wild-type and four p $75^{\text {NTR }}$ mutant embryos]. As described in a previous study, peripheral axons in Sema3A-null mice overshot the front observed in wild-type embryos (Fig. 6A, supplemental Figs. 3, 4, available at www.jneurosci.org as supplemental material). In p $75^{\mathrm{NTR}}$ mutant embryos, which are also Sema3A-/-, the peripheral axons overshot the front observed in wild-type embryos. The innervation pattern in these mice is, in most cases, similar to that found in the Sema3A-null embryos (Fig. 6A, supplemental Figs. 3, 4, available at www.jneurosci.org as supplemental material). The differences between $\mathrm{p} 75^{\mathrm{NTR}}-/-$ and $\mathrm{p} 75^{\mathrm{NTR} /}$ 
A wt

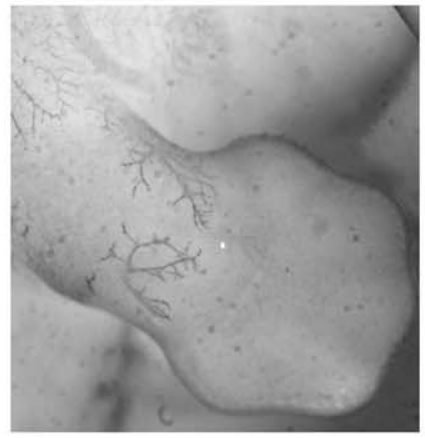

Sema3A -/- Sema3A -/- p75 -/-
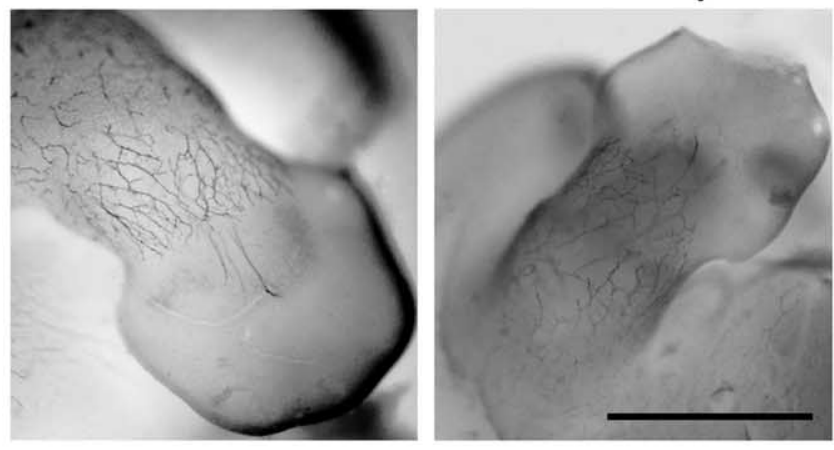

B

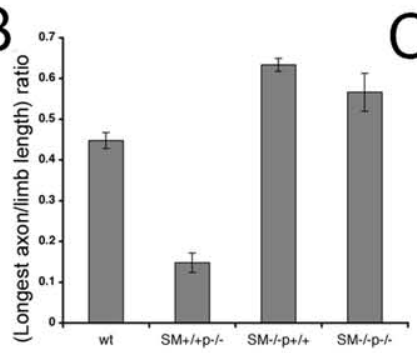

$\mathrm{D}$

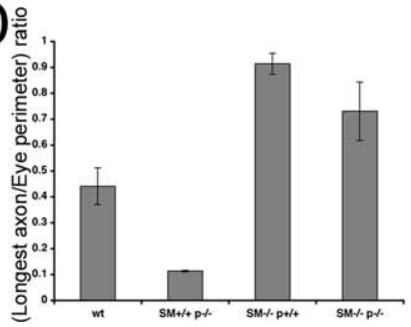

Figure 6. Growth inhibition of peripheral sensory projections in p75 ${ }^{\text {NTR }}$ mutant embryos is alleviated in the absence of Sema3A. Whole-mount anti-neurofilament immunohistochemistry was performed on E12.5 embryos. $\boldsymbol{A}$, Peripheral nerves in hind limbs. Peripheral nerves in $\mathrm{p} 75^{\mathrm{NTR}}$ mutant mice are severely stunted (top right), compared with those of control wild-type littermates (top left). In contrast, in p75 ${ }^{\text {NTR }}$ mutant mice that were also Sema3A-null (bottom right), peripheral axons overshot the front observed in wild-type embryos, similar to the overshooting observed in Sema3A-null mice that are wild-type for the $\mathrm{p} 75^{\mathrm{NTR}}$ gene (bottom left). Scale bar, $1 \mathrm{~mm}$. B-D, Quantification of relative innervation of hind limbs (representative whole mount shown in $\boldsymbol{A}$ ) forelimbs (whole mount shown in S3) and trigeminal ganglia (whole mount shown in S4) using whole-mount anti-neurofilament immunohistochemistry. To quantify the axon growth capacity of each genotype, we measured the length of the longest axon. $\boldsymbol{B}, \boldsymbol{C}$, The length of the longest axon measured from the base of the limb and normalized to the length of the hind limb $(\boldsymbol{B})$ or forelimb $(\boldsymbol{C})$. D , The length of the longest axon from the trigeminal ganglion normalized to the eye perimeter. Results represent the means \pm SEM of seven wild-type embryos, 15 Sema3A mutants, four p $75^{\text {NTR }}$ mutants and five Sema3A/p75 NTR double-mutant embryos from a total of eight litters.
Sema3A double-mutant embryos were significant $[p=0.008$ (hind limb), $p=0.008$ (forelimbs), and $p=0.032$ (trigeminal ganglion), as determined by a two-tailed Mann-Whitney $U$ test with four $\mathrm{p} 75^{\mathrm{NTR}}$ mutant and five Sema3A/p75 NTR double-mutant embryos]. The differences between Sema3A mutant embryos and $\mathrm{p} 75^{\mathrm{NTR}} /$ Sema3A double-mutant embryos were not significant $[p=0.338$ (hind limb), $p=0.672$ (forelimbs), and $p=0.412$ (trigeminal ganglion), as determined by a two-tailed Mann-Whitney $U$ test with 15 Sema3A mutants and five Sema3A/p $75^{\text {NTR }}$ double-mutant embryos]. In addition to measuring the longest axon, we also calculated the total axon length per limb using stereological principles (data not shown) (Fig. 7F) (for details, see Materials and Methods). For the most part, these results were similar to the length-of-the-longest-axon data. However, the density of axons in the double-mutant mice 2.28 -fold greater for hind limbs and 1.74-fold for forelimbs, compared with the wildtype) was an intermediate value between the wild-type and the Sema3A mutant (5.97-fold for hind limbs and 3.74-fold for forelimbs, compared with the wild-type). This intermediate phenotype for total axon length indicates that the Sema3Anull phenotype is not simply dominant over the $\mathrm{p} 75^{\mathrm{NTR}} \mathrm{mu}-$ tant phenotype, but rather that Sema3A and $\mathrm{p} 75^{\mathrm{NTR}}$ interact genetically with regard to axon growth regulation. The lower density of axons observed in the double-mutant mice, compared with that observed in the Sema3A mutant, may reflect the massive decrease in the number of peripheral sensory neurons in the $\mathrm{p} 75^{\mathrm{NTR}}$ mutant (Lee et al., 1992; von Schack et al., 2001). However, it is possible that the differences between the axon density results and the longest growth measurements reflect Sema3A-related effects.

\section{Growth inhibition of peripheral sensory projections in $\mathrm{p} 75^{\mathrm{NTR}}$} mutant mice is sensitive to changes in the level of Sema3A

Haplo-insufficiency in the semaphorin family has been described for Sema3B and Neuropilin2-null mice (Zou et al., 2000; Falk et al., 2005). In Sema3A mutant mice, mRNA levels in heterozygous mice are reduced by half and are so low as to be nearly undetectable in the homozygous mutant mice (Behar et al., 1996; Taniguchi et al., 1997). Because our results suggest that $p 75^{\text {NTR }}$ affects the level of Sema3A activity, we wanted to test whether reduction of Sema3A levels in vivo would suppress the inhibition of sensory axons in $\mathrm{p} 75^{\mathrm{NTR}}$ mutant mice. We, therefore, examined the effect of Sema3A levels on peripheral nerve growth in the absence of p $75^{\text {NTR }}$. Using whole-mount antineurofilament immunohistochemistry, we compared peripheral innervation in E12.5 p $75^{\mathrm{NTR}}-/-$ Sema3A $+/-$ embryos and E12.5 p75 ${ }^{\mathrm{NTR}}-/-$ Sema3A $+1+$ embryos (Fig. 7). As shown in Figure 6, in p $75^{\mathrm{NTR}}-/-$ Sema3A $+/+$ mice, peripheral nerves at E12.5 were severely stunted. However, in $75^{\mathrm{NTR}}-/-$ Sema3A $+/-$ animals, E12.5 peripheral nerves grew better (Fig. 7, supplemental Fig. 5, available at www.jneurosci.org as supplemental material). This axon growth improvement in $75^{\mathrm{NTR}}-/-$ Sema3A $+/-$ animals is not simply a result of increased growth in Sema3A heterozygous embryos, because $75^{\mathrm{NTR}}+/+$ Sema3A $+/-$ exhibited only slightly increased growth (1.19-fold for hind limbs, 1.25-fold for forelimbs and 1.19-fold trigeminal ganglion), compared with that of wild-type embryos (data not shown). In contrast, p $75^{\mathrm{NTR}}-/-$ Sema3A $+/-$ showed a significantly greater increase in growth compared with $\mathrm{p} 75^{\mathrm{NTR}}-/-$ Sema3A $+/+$ (threefold for hind limbs, 2.7-fold for forelimbs, and 4.4-fold for trigeminal ganglion). The difference between $\mathrm{p} 75^{\mathrm{NTR}}-/-$ Sema $3 \mathrm{~A}+/+$ and $\mathrm{p} 75^{\mathrm{NTR}}-/-$ Sema $3 \mathrm{~A}+/-$ mutant embryos is 
significant $\left[p=1.25 \times 10^{-4}\right.$ (hind limb), $p=1.25 \times 10^{-4}$ (forelimbs), and $p=$ 0.005 (trigeminal ganglion), as determined by a one-tailed Mann-Whitney $U$ test with four $\mathrm{p} 75^{\mathrm{NTR}}-/-$ mutant and seven Sema3A+/- p75 ${ }^{\mathrm{NTR}}-/-$ mutant embryos]. In fact, it appears that p $75^{\text {NTR }}-1-$ Sema3A+/ - embryos are not significantly different from those of wild-type mice $\left[\mathrm{p} 75^{\mathrm{NTR}}+/+\right.$ Sema3A $+/+p=0.579$ (hind limb), $p=$ 0.438 (forelimbs), and $p=0.931$ (trigeminal ganglion) as determined by a twotailed Mann-Whitney $U$ test with seven wild-type and seven Sema3A+/p75 ${ }^{\text {NTR }}$ - / - embryos].

Axon growth in vitro of $\mathrm{p} 75^{\mathrm{NTR}}$ heterozygous mutants showed an intermediate response for Sema3A (Fig. 1). It is therefore possible that $\mathrm{p} 75^{\mathrm{NTR}}$ heterozygous mutants will grow less also in vivo, compared with wild-type littermates. To address this question, we measured the longest axon in $\mathrm{p} 75^{\mathrm{NTR}}$ heterozygous mutants and wild-type controls. We found no significant difference between these two genotypes (data not shown). To investigate this possibility more carefully we also calculated the total axon length per limb using stereological principles (Fig. $7 F$ ) (for details, see Materials and Methods). We detected a reduction in axon growth according to the number of $\mathrm{p} 75^{\text {NTR }}$ alleles (which likely corresponds to the levels of p75 ${ }^{\text {NTR }}$ expression) for both the forelimbs and hind limbs. In fact, heterozygous mutants exhibited intermediate nerve coverage between wild-type and $\mathrm{p} 75^{\mathrm{NTR}-1-}$. This trend in the nerve coverage of the p75 ${ }^{\text {NTR }}$ genotypes was statistically significant (forelimbs, $p=0.001$; hind limbs, $p=$ 0.01 , Jonckheere-Terpstra test). Consistent with the longest axon criteria, the density of axons in the Sema $3 \mathrm{~A}+1-$ p75 ${ }^{\text {NTR }}-1-$ embryos was similar to the wild-type levels (1.07-fold greater for hind limbs and 1.47-fold for forelimbs, compared with the wild-type) (Fig. $7 F$ ), indicating that the absence of one Sema3A allele is sufficient to bring the growth capacity of $\mathrm{p} 75^{\mathrm{NTR}}-/-$ mutants to wild-type levels. As mentioned above, this is not the case with the Sema3A - / - p $75^{\text {NTR }}-1-$ embryos. This difference in the relationship between the axon density and longest axon results in the two genotypes may reflect the multifunctional role of both genes in peripheral nerve patterning.
A wt

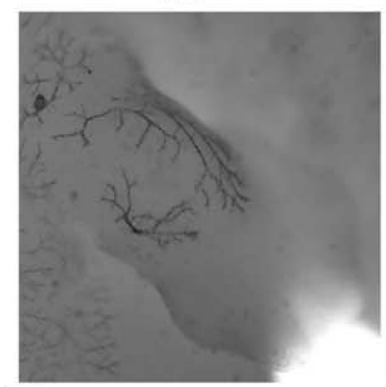

B

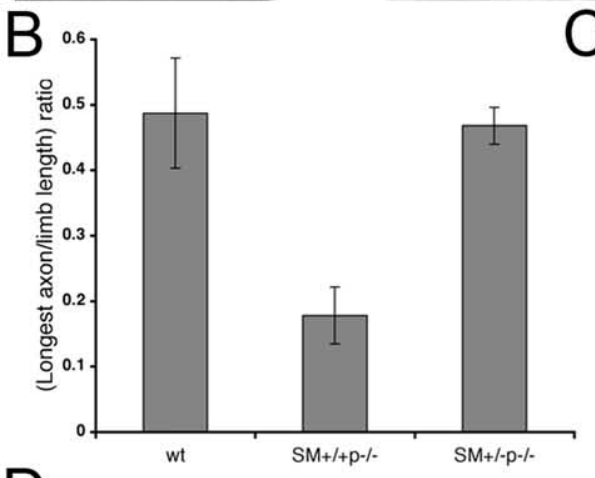

D

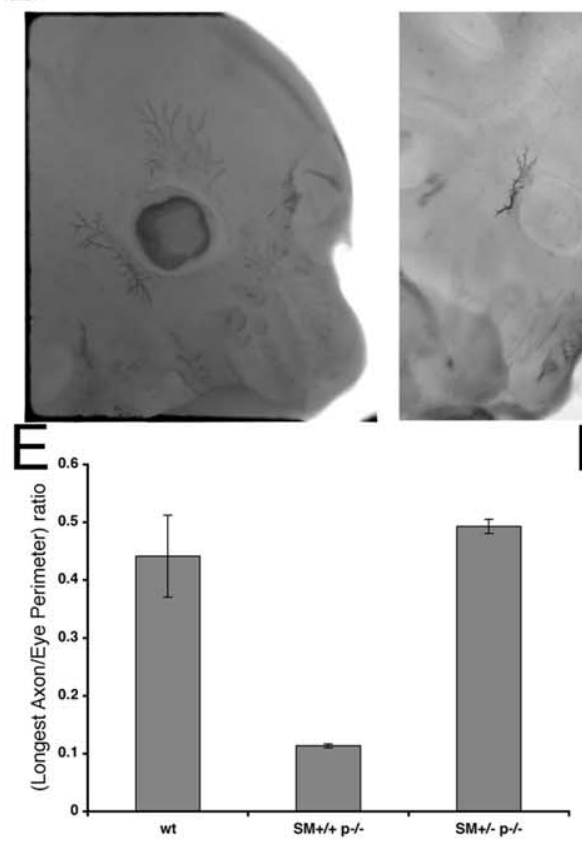

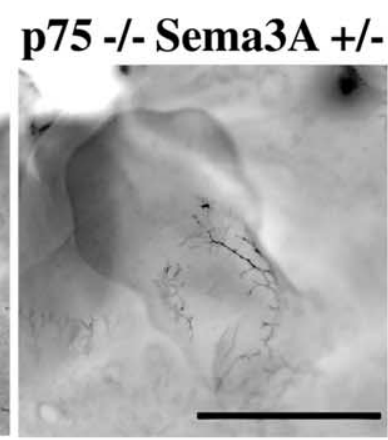

C

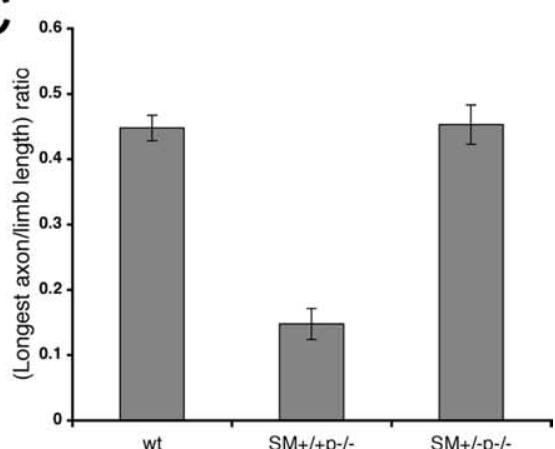

wt

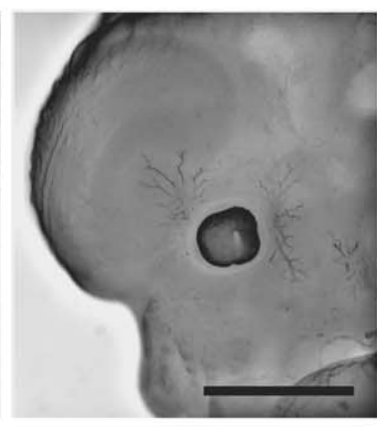

$\mathrm{F}$

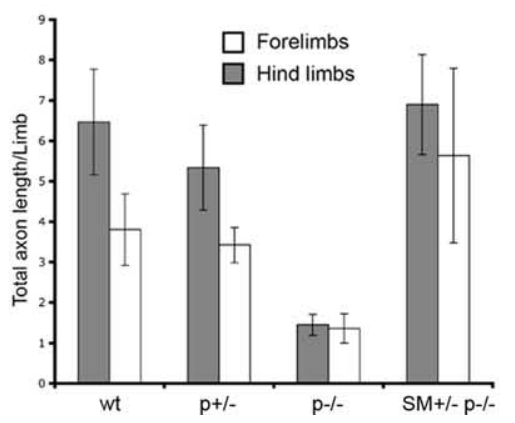

Figure 7. Growth inhibition of peripheral sensory projections in $\mathrm{p} 75^{\mathrm{NTR}}$ mutant mice is sensitive to changes in Sema3A levels. Whole-mount anti-neurofilamentimmunohistochemistry was performed onE12.5 embryos. $\boldsymbol{A}, \boldsymbol{D}$, Peripheral nervesinforelimbs $(\boldsymbol{A})$ and trigeminal ganglia $(\boldsymbol{D})$ are shown. Compared with those of the control wild-type littermates (left), peripheral nerves in $175^{\mathrm{NTR}}$ mutant mice (middle) were severely stunted. In contrast, p75 $5^{\mathrm{NTR}}-1-$, Sema3A+1- mutant mice (right) resemble their wild-type littermates. $\boldsymbol{B}, \boldsymbol{C}, \boldsymbol{E}$, Quantification of relative innervation of forelimbs $(\boldsymbol{A})$, trigeminal ganglia $(\boldsymbol{D})$ and hind limbs (S5) using whole-mount anti-neurofilament immunohistochemistry. We again used the longest axon length normalized to the length of the $\operatorname{limb}(\boldsymbol{B}, \boldsymbol{C})$ or the eye perimeter $(\boldsymbol{E})$ to quantify the axon growth capacity of each genotype. Forelimbs $(\boldsymbol{B})$, hind limbs ( $)$, and trigeminal ganglion (E) are shown. $\boldsymbol{F}$, Quantification of total axon lengths in forelimbs (gray bars) and hind limbs (empty bars) was estimated using Buffon's needle problem equation (see Materials and Methods). Results represent the means \pm SEM of seven wild-type, three $75^{\text {NTR }}+1-$, four $75^{\text {NTR }}-1-$ mutant (wild type and p $75^{\text {NTR }}-1-$ mutant are the same embryos used for Fig. 6), and seven Sema3A+/-, p75 $5^{\text {NTR }}-1-$ embryos. Scale bar, $1 \mathrm{~mm}$.

\section{Discussion}

Previous work has shown that $\mathrm{p} 75^{\mathrm{NTR}}$ is a necessary component of peripheral axon growth and patterning (Yamashita et al., 1999; Bentley and Lee, 2000). The mechanism by which $\mathrm{p} 75^{\mathrm{NTR}}$ is in- volved in this process is not entirely clear. Here, we investigated whether $\mathrm{p} 75^{\mathrm{NTR}}$ plays a role in Sema3A activity and whether this possible link might explain the effects of $\mathrm{p} 75^{\mathrm{NTR}}$ on axon growth. 


\section{P75 ${ }^{\text {NTR }}$ expression reduces sensitivity to Sema3A repellent activity}

Our results show that embryonic sensory neurons of homozygous p $75^{\text {NTR }}$ mutant mice are significantly more sensitive to Sema3A activity than those of wild-type sensory neurons, as shown both in a collapse and in neurite outgrowth assays. This difference is shown most dramatically by the results of the growth assay. In this assay, we found that, at certain low concentrations of Sema3A, neurons of homozygous p $75^{\text {NTR }} \mathrm{mu}$ tants almost stop growing whereas wild-type sensory neurons continue to grow. Under such conditions, the difference in total growth between the two genotypes is enormous, a result consistent with the growth differences observed in the different $\mathrm{p} 75^{\mathrm{NTR}}$ and Sema3A genotypes. Although this specific p $75^{\text {NTR }}$ mouse mutant (lacking exon III) may still express a minor splice variant of $\mathrm{p} 75^{\mathrm{NTR}}$, there are several reasons to believe that the increased sensitivity we detected in these neurons is probably attributable to their lack of $\mathrm{p} 75^{\mathrm{NTR}}$ activity. First, this residual splice variant $\left(s-p 75^{N T R}\right)$ was detected in Schwann cells (von Schack et al., 2001), but not in embryonic DRG growth cones (by immunohistochemistry) or embryonic brain tissue (examined using Western blots), indicating that $\mathrm{s}-\mathrm{p} 75^{\mathrm{NTR}}$ is not present at the relevant stage and/or in the relevant neuronal population (Gehler et al., 2004). Second, s-p75 ${ }^{\text {NTR }}$ does not bind neurotrophins (von Schack et al., 2001; Paul et al., 2004). Thirdly, DRG neurons from the p75 ${ }^{\text {ExonIII }}$-mutant animal respond differently than wild-type neurons to Nogo and MAG (Wang et al., 2002; Wong et al., 2002 ), suggesting that $\mathrm{p} 75^{\mathrm{NTR}}$ in these neurons is not functional. Furthermore, the inhibition of Sema3A collapse activity in the COS cell assay as a result of $\mathrm{p} 75^{\mathrm{NTR}}$ expression independently supports the idea that $\mathrm{p} 75^{\mathrm{NTR}}$ is a negative modulator of Sema3A repellent activity.

\section{The mechanism of $\mathrm{p} 75^{\mathrm{NTR}}$ modulation of Sema3A activity}

NGF and BDNF are both known to modulate Sema3A repellent activity (Tuttle and O'Leary, 1998; Dontchev and Letourneau, 2002). It is, therefore, possible that $\mathrm{p} 75^{\mathrm{NTR}}$ modulation of Sema3A repulsion is related to direct activation of $\mathrm{p} 75^{\mathrm{NTR}}$ by neurotrophins or indirect activation by increased activation of Trk receptors. Two lines of evidence indicate that p $75^{\text {NTR }}$ modulation activity is at least partially neurotrophinindependent. First, NGF is able to reduce Sema3A activity equally well in both wild-type and $\mathrm{p} 75^{\mathrm{NTR}}$ mutant neurons. This result indicates that although NGF modulates Sema3A, this activity is not related to $\mathrm{p} 75^{\mathrm{NTR}}$. Second, expression of p $75^{\text {NTR }}$ in a COS cell contraction assay modulates Sema3A activity. If the effect of $\mathrm{p} 75^{\mathrm{NTR}}$ modulation is mostly independent of NGF, then how can this molecule affect Sema3A activity? One possible mechanism may involve RhoA activation. Sema3A-induced activity is mediated by activation of RhoA (Wu et al., 2005). p75 ${ }^{\text {NTR }}$ activity is also related to RhoA. For instance, inhibition of axon growth by Nogo-66 or MAG via the Nogo-66 receptor/Lingo-1/p75 ${ }^{\text {NTR }}$ complex is mediated by RhoA activation (Yamashita et al., 2002; Yamashita and Tohyama, 2003). Moreover, it has been shown that when p $75^{\text {NTR }}$ is not bound to neurotrophins, it can activate RhoA (Yamashita et al., 1999; Gehler et al., 2004). However, it was also shown that levels of activated RhoA in growth cones and cerebellar cell extracts of p $75^{\text {NTR }}$ mutant mice are lower than in wild-type neurons (Gehler et al., 2004). Because Sema3A activity requires activation of RhoA, it would be expected that neurons from $\mathrm{p} 75^{\mathrm{NTR}}$ mutant mice would be less sensitive to
Sema3A-induced growth cone collapse. However, we found that $\mathrm{p} 75^{\mathrm{NTR}}$ neurons are actually more sensitive to Sema3Ainduced collapse. Therefore, RhoA activation is probably not the cause of this effect.

How then does $\mathrm{p} 75^{\mathrm{NTR}}$ modulate Sema3A activity? The results of our immunostaining for $\mathrm{p} 75^{\mathrm{NTR}}$ and NP1 indicate that p $75^{\text {NTR }}$ can be found in close proximity to the Sema3A receptor in growth cones and axons. This colocalization significantly increases in response to Sema3A, most prominently in Sema3Ainduced NP1 clusters, which are believed to be involved with Sema3A receptor activation (Fournier et al., 2000). Moreover, the ability of $\mathrm{p} 75^{\mathrm{NTR}}$ to immunoprecipitate PlexinA4 and NP1 implies that $\mathrm{p} 75^{\mathrm{NTR}}$ may directly modulate the Sema3A receptor complex. Sema3A binds a complex receptor comprised of two essential components, plexin and NP1. The reduction in the ability of PlexinA4 to immunoprecipitate NP1 as a function of increasing $\mathrm{p} 75^{\mathrm{NTR}}$ concentration suggests that interaction between p $75^{\mathrm{NTR}}$ and either NP1 or PlexinA4 can inhibit the interaction between NP1 and PlexinA4. Moreover, the increase in the amount of $\mathrm{p} 75^{\mathrm{NTR}}$ immunoprecipitated with PlexinA4 as coimmunoprecipitation of NP1 decreases implies that $\mathrm{p} 75^{\mathrm{NTR}}$ can compete with NP1 in binding PlexinA4, thereby reducing levels of functional Sema3A receptor complex. However, because we were unable to detect this interaction in neurons, alternative explanations such as $\mathrm{p} 75^{\mathrm{NTR}}$ indirectly modulating Sema3A activity, cannot be ruled out.

\section{Cross talk between p75 ${ }^{\mathrm{NTR}}$ and Sema3A activity is an important modulator of sensory innervation in the developing embryo}

Previous studies have found that peripheral axons are severely stunted in p75 ${ }^{\text {NTR }}$ mutant embryos (Yamashita et al., 1999; Bentley and Lee, 2000). In vitro, sensory neurons from the p $75^{\text {NTR }}$ mutant mice grown on adult sciatic nerve cryosections showed a $12 \%$ reduction in growth capacity (Bentley and Lee, 2000). Based on this result, it was suggested that an intrinsic reduction in neurite elongation ability causes the dramatic reduction in innervation by sensory axons in $\mathrm{p} 75^{\mathrm{NTR}}$ mutant mice. Alternatively, p75 ${ }^{\mathrm{NTR}}$ mutant neurons could be more sensitive to a component of the sciatic nerve substratum, leading to reduced growth. Consistent with this idea, another study found that outgrowth of DRG neurites from $\mathrm{p} 75^{\text {NTR }}$ mutants was indistinguishable from that of wild-type DRG neurites (Gehler et al., 2004). In this case, the reduction is a result of an extrinsic factor found in the sciatic nerve. [Interestingly, Sema3A expression has been detected in sciatic nerve cells after injury (Scarlato et al., 2003).] The result presented here regarding sensitivity to Sema3A repellent activity suggests that the dramatic reduction in axon elongation may be, at least in part, the result of extrinsic factors. This possibility is strongly supported by our in vivo results, which show that the Sema3A mutant is able to compensate for the $\mathrm{p} 75^{\mathrm{NTR}}$ mutant phenotype with regard to the degree of axon growth. Because

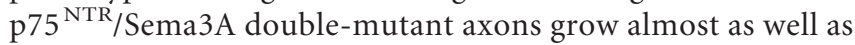
Sema3A mutant axons, it appears that the lack of axon growth in $\mathrm{p} 75^{\mathrm{NTR}}$ mutants is the result of the extrinsic levels of Sema3A expression. Careful analysis of the Sema3A+/p $75^{\mathrm{NTR}}+/+$ embryos revealed a slight increase in axon growth of $\sim 20 \%$, compared with that of wild-type embryos. However, Sema3A+/ - p75 ${ }^{\mathrm{NTR}}-1-$ embryos showed an increase of $\sim 240 \%$ in axon growth (as evaluated by the longest axon measurement) compared with Sema $3 \mathrm{~A}+/+$ p $75^{\mathrm{NTR}}-/-$ embryos, indicating that this phenotype is very similar to that of 
the wild-type in terms of axon growth. This finding supports the possibility of an interaction between the $\mathrm{p} 75^{\mathrm{NTR}}$ and Sema3A genes.

In summary, the results of our colocalization experiments and the biochemical data are consistent with a model in which p $75^{\text {NTR }}$ acts as a competitive inhibitor for the Sema3A receptor complex, modulating the activity of this complex. Nevertheless, alternative explanations cannot be ruled out. However, considering the genetic and the cell biology results, it is clear that $\mathrm{p} 75^{\mathrm{NTR}}$ is a functional modulator of Sema3A activity and, in its absence, sensory neurons are overly influenced by Sema3A, resulting in severe growth redundancy.

\section{p $75^{\text {NTR }}$ in nerve regeneration: a double-edged sword?}

The inability of adult mammalian CNS neurons to regenerate after injury is due, at least in part, to axonal repulsion signals from the environment (Schwab and Bartholdi, 1996). Important inhibitory molecules include the myelin-associated molecules, MAG, OMgP, and Nogo-66. All three of these proteins exert their inhibitory activities by binding to a neuronal receptor complex containing the Nogo-66 receptor, Lingo-1, and p75 ${ }^{\text {NTR }}$ (Wang et al., 2002; Wong et al., 2002). (p75 ${ }^{\text {NTR }}$ can be replaced in this complex by another member of the TNF receptor superfamily, Troy.) Therefore, inhibition of $\mathrm{p} 75^{\text {NTR }}$ has been proposed as a target for efforts to improve regeneration of CNS neurons by blocking myelin inhibitory activity. Sema3A expression is induced at the site of CNS injury and accumulating evidence suggests that it is also involved in inhibition of axon regeneration (Pasterkamp et al., 1999; De Winter et al., 2002; Kikuchi et al., 2003). In this study, we show that $\mathrm{p} 75^{\mathrm{NTR}}$ is a negative modulator of the Sema3A repulsion complex. In its absence, the sensitivity of neurons to Sema3A activity increases. Therefore, strategies for inhibiting $\mathrm{p} 75^{\mathrm{NTR}}$ to inhibit myelin-associated molecules will strengthen Sema3A activity, but the net result may not improve regeneration capacity. We, therefore, suggest that other components of the myelin-associated receptor complex may be more appropriate targets for efforts to improve neuronal regeneration capacity.

\section{References}

Bandtlow C, Dechant G (2004) From cell death to neuronal regeneration, effects of the p75 neurotrophin receptor depend on interactions with partner subunits. Sci STKE 2004:pe24.

Behar O, Golden JA, Mashimo H, Schoen FJ, Fishman MC (1996) Semaphorin III is needed for normal patterning and growth of nerves, bones and heart. Nature 383:525-528.

Behar O, Mizuno K, Badminton M, Woolf CJ (1999) Semaphorin 3A growth cone collapse requires a sequence homologous to tarantula hanatoxin. Proc Natl Acad Sci USA 96:13501-13505.

Bentley CA, Lee KF (2000) p75 is important for axon growth and Schwann cell migration during development. J Neurosci 20:7706-7715.

Ben-Zvi A, Yagil Z, Hagalili Y, Klein H, Lerman O, Behar O (2006) Semaphorin $3 \mathrm{~A}$ and neurotrophins: a balance between apoptosis and survival signaling in embryonic DRG neurons. J Neurochem 96:585-597.

Bergmann I, Priestley JV, McMahon SB, Brocker EB, Toyka KV, Koltzenburg M (1997) Analysis of cutaneous sensory neurons in transgenic mice lacking the low affinity neurotrophin receptor p75. Eur J Neurosci 9:18-28.

De Winter F, Oudega M, Lankhorst AJ, Hamers FP, Blits B, Ruitenberg MJ, Pasterkamp RJ, Gispen WH, Verhaagen J (2002) Injury-induced class 3 semaphorin expression in the rat spinal cord. Exp Neurol 175:61-75.

Dontchev VD, Letourneau PC (2002) Nerve growth factor and semaphorin $3 \mathrm{~A}$ signaling pathways interact in regulating sensory neuronal growth cone motility. J Neurosci 22:6659-6669.

Falk J, Bechara A, Fiore R, Nawabi H, Zhou H, Hoyo-Becerra C, Bozon M,
Rougon G, Grumet M, Puschel AW, Sanes JR, Castellani V (2005) Dual functional activity of semaphorin $3 \mathrm{~B}$ is required for positioning the anterior commissure. Neuron 48:63-75.

Fournier AE, Nakamura F, Kawamoto S, Goshima Y, Kalb RG, Strittmatter SM (2000) Semaphorin3A enhances endocytosis at sites of receptor-F-actin colocalization during growth cone collapse. J Cell Biol 149:411-422.

Gehler S, Gallo G, Veien E, Letourneau PC (2004) p75 neurotrophin receptor signaling regulates growth cone filopodial dynamics through modulating RhoA activity. J Neurosci 24:4363-4372.

Kikuchi K, Kishino A, Konishi O, Kumagai K, Hosotani N, Saji I, Nakayama C, Kimura T (2003) In vitro and in vivo characterization of a novel semaphorin 3A inhibitor, SM-216289 or xanthofulvin. J Biol Chem 278:42985-42991.

Kitsukawa T, Shimizu M, Sanbo M, Hirata T, Taniguchi M, Bekku Y, Yagi T, Fujisawa H (1997) Neuropilin-semaphorin III/D-mediated chemorepulsive signals play a crucial role in peripheral nerve projection in mice. Neuron 19:995-1005.

Lee KF, Li E, Huber LJ, Landis SC, Sharpe AH, Chao MV, Jaenisch R (1992) Targeted mutation of the gene encoding the low affinity NGF receptor p75 leads to deficits in the peripheral sensory nervous system. Cell 69:737-749.

Lee KF, Bachman K, Landis S, Jaenisch R (1994) Dependence on p75 for innervation of some sympathetic targets. Science 263:1447-1449.

Mandarim-de-Lacerda CA (2003) Stereological tools in biomedical research. An Acad Bras Cienc 75:469-486.

McQuillen PS, DeFreitas MF, Zada G, Shatz CJ (2002) A novel role for p75NTR in subplate growth cone complexity and visual thalamocortical innervation. J Neurosci 22:3580-3593.

Nakamura F, Kalb RG, Strittmatter SM (2000) Molecular basis of semaphorin-mediated axon guidance. J Neurobiol 44:219-229.

Nykjaer A, Willnow TE, Petersen CM (2005) p75NTR-live or let die. Curr Opin Neurobiol 15:49-57.

Pasterkamp RJ, Giger RJ, Ruitenberg MJ, Holtmaat AJ, De Wit J, De Winter F, Verhaagen J (1999) Expression of the gene encoding the chemorepellent semaphorin III is induced in the fibroblast component of neural scar tissue formed following injuries of adult but not neonatal CNS. Mol Cell Neurosci 13:143-166.

Paul CE, Vereker E, Dickson KM, Barker PA (2004) A pro-apoptotic fragment of the p75 neurotrophin receptor is expressed in p75NTRExonIV null mice. J Neurosci 24:1917-1923.

Ronn LC, Ralets I, Hartz BP, Bech M, Berezin A, Berezin V, Moller A, Bock E (2000) A simple procedure for quantification of neurite outgrowth based on stereological principles. J Neurosci Methods 100:25-32.

Scarlato M, Ara J, Bannerman P, Scherer S, Pleasure D (2003) Induction of neuropilins-1 and -2 and their ligands, Sema3A, Sema3F, and VEGF, during Wallerian degeneration in the peripheral nervous system. Exp Neurol 183:489-498.

Schwab ME, Bartholdi D (1996) Degeneration and regeneration of axons in the lesioned spinal cord. Physiol Rev 76:319-370.

Suto F, Ito K, Uemura M, Shimizu M, Shinkawa Y, Sanbo M, Shinoda T, Tsuboi M, Takashima S, Yagi T, Fujisawa H (2005) Plexin-a4 mediates axon-repulsive activities of both secreted and transmembrane semaphorins and plays roles in nerve fiber guidance. J Neurosci 25:3628-3637.

Takahashi T, Fournier A, Nakamura F, Wang LH, Murakami Y, Kalb RG, Fujisawa H, Strittmatter SM (1999) Plexin-neuropilin-1 complexes form functional semaphorin-3A receptors. Cell 99:59-69.

Tamagnone L, Artigiani S, Chen H, He Z, Ming GI, Song H, Chedotal A, Winberg ML, Goodman CS, Poo M, Tessier-Lavigne M, Comoglio PM (1999) Plexins are a large family of receptors for transmembrane, secreted, and GPI-anchored semaphorins in vertebrates. Cell 99:71-80.

Tang XQ, Tanelian DL, Smith GM (2004) Semaphorin3A inhibits nerve growth factor-induced sprouting of nociceptive afferents in adult rat spinal cord. J Neurosci 24:819-827.

Taniguchi M, Yuasa S, Fujisawa H, Naruse I, Saga S, Mishina M, Yagi T (1997) Disruption of semaphorin III/D gene causes severe abnormality in peripheral nerve projection. Neuron 19:519-530.

Togashi H, Schmidt EF, Strittmatter SM (2006) RanBPM contributes to Semaphorin3A signaling through plexin-A receptors. J Neurosci 26:4961-4969. 
Turner LJ, Hall A (2006) Plexin-induced collapse assay in COS cells. Methods Enzymol 406:665-676.

Tuttle R, O'Leary DD (1998) Neurotrophins rapidly modulate growth cone response to the axon guidance molecule, collapsin-1. Mol Cell Neurosci 11:1-8.

Ulupinar E, Datwani A, Behar O, Fujisawa H, Erzurumlu R (1999) Role of semaphorin III in the developing rodent trigeminal system. Mol Cell Neurosci 13:281-292.

von Schack D, Casademunt E, Schweigreiter R, Meyer M, Bibel M, Dechant G (2001) Complete ablation of the neurotrophin receptor p75NTR causes defects both in the nervous and the vascular system. Nat Neurosci 4:977-978.

Wang KC, Kim JA, Sivasankaran R, Segal R, He Z (2002) P75 interacts with the Nogo receptor as a co-receptor for Nogo, MAG and OMgp. Nature 420:74-78.

Wen Z, Zheng JQ (2006) Directional guidance of nerve growth cones. Curr Opin Neurobiol 16:52-58.

White FA, Behar O (2000) The development and subsequent elimination of aberrant peripheral axon projections in Semaphorin3A null mutant mice. Dev Biol 225:79-86.

Wong ST, Henley JR, Kanning KC, Huang KH, Bothwell M, Poo MM (2002)
A p75(NTR) and Nogo receptor complex mediates repulsive signaling by myelin-associated glycoprotein. Nat Neurosci 5:1302-1308.

Wu KY, Hengst U, Cox LJ, Macosko EZ, Jeromin A, Urquhart ER, Jaffrey SR (2005) Local translation of RhoA regulates growth cone collapse. Nature 436:1020-1024.

Yamashita T, Tohyama M (2003) The p75 receptor acts as a displacement factor that releases Rho from Rho-GDI. Nat Neurosci 6:461-467.

Yamashita T, Tucker KL, Barde YA (1999) Neurotrophin binding to the p75 receptor modulates Rho activity and axonal outgrowth. Neuron 24:585-593.

Yamashita T, Higuchi H, Tohyama M (2002) The p75 receptor transduces the signal from myelin-associated glycoprotein to Rho. J Cell Biol 157:565-570.

Yaron A, Huang PH, Cheng HJ, Tessier-Lavigne M (2005) Differential requirement for Plexin-A3 and -A4 in mediating responses of sensory and sympathetic neurons to distinct class 3 Semaphorins. Neuron 45:513-523.

Zou Y, Stoeckli E, Chen H, Tessier-Lavigne M (2000) Squeezing axons out of the gray matter: a role for slit and semaphorin proteins from midline and ventral spinal cord. Cell 102:363-375. 